\title{
Real-Time Regional Jet Comprehensive Aero-Icing Analysis via Reduced-Order Modeling
}

\author{
Zhao Zhan ${ }^{1}$, Wagdi G. Habashi ${ }^{2}$ and Marco Fossati ${ }^{3}$ \\ CFD Laboratory, Department of Mechanical Engineering, McGill University, Montreal, Quebec, Canada H3A 2S6
}

\begin{abstract}
This paper presents a reduced-order modeling framework based on proper orthogonal decomposition, multi-dimensional interpolation and machine learning algorithms, along with an error driven iterative sampling method, to adaptively select an optimal set of snapshots in the context of in-flight icing certification. The methodology is applied, to the best of our knowledge for the first time, to a "complete" aircraft and to the "entire" icing certification envelope, providing invaluable additional data to the ones from icing tunnels or natural flighttesting. This systematic methodology is applied to the shape/mass of ice, and to the aerodynamics penalties in terms of lift, drag and pitching moments. The level of accuracy achieved strongly supports the drive to incorporate more computational fluid dynamics information into in-flight icing certification and pilot training programs, leading to increased aviation safety.
\end{abstract}

\section{Introduction}

In-flight icing encounters pose substantial risks to aviation safety [1]. As a consequence of the accretion of ice on wings and/or other critical surfaces, lift decreases, drag increases, and the center of gravity shifts. These adverse effects will degrade the aerodynamic performance and controllability of the airplane, resulting in incidents and accidents. From 1996 to 2008, the National Transportation Safety Board (NTSB) had issued 82 icing-related recommendations to the Federal Aviation Administration (FAA), based on its aviation accident investigations [2]. For instance, following the 1997 fatal crash of Comair Airlines Flight 3272 near Monroe, Michigan, the NTSB called for FAA to “(A-98-92) Conduct research to identify realistic ice accumulations and determine the effects and dangers of such ice

\footnotetext{
${ }^{1} \mathrm{Ph} . D$. candidate, Department of Mechanical Engineering, 688 Sherbrooke Street West.

${ }^{2}$ Professor and Director CFD Laboratory, Department of Mechanical Engineering, 688 Sherbrooke Street West, and President, CERTIF-ICE Inc., AIAA Fellow.

${ }^{3}$ Associate Director CFD Laboratory, Department of Mechanical Engineering, 688 Sherbrooke Street West, AIAA Member.
} 
accumulations. The information developed through such research should be incorporated into aircraft certification requirements and pilot training programs." More recently, following the 2009 crash of Empire Airlines Flight 8284 in Lubbock, Texas, the NTSB made recommendations that put more emphasis on pilot training: "(A-11-46) Define and codify minimum simulator model fidelity requirements for aerodynamic degradations resulting from airframe ice accumulation. These requirements should be consistent with performance degradations that the National Transportation Safety Board and other agencies have extracted during the investigations of icing accidents and incidents." [3] Among NTSB's icing-related recommendations to the FAA, rigorous aircraft in-flight icing certification, as well as realistic, thorough, training for pilots to recognize and deal with degraded flight characteristics due to airframe icing, are recognized as being key factors, and challenges, in reducing risks posed to aviation safety by icing.

Icing effects on aircraft are assessed through an extensive procedure intended to ensure safe operation for conditions specified in the icing envelopes described in the appendix $\mathrm{C}$ of the Title 14, Code of Federal Regulations Part 25 [4], as well as in the new appendices D \& O [5]. These icing envelopes specify atmospheric icing conditions in terms of pressure altitude, temperature, liquid water content (LWC) and water droplet median volumetric diameter (MVD). The traditional icing certification process includes numerical and wind/icing tunnel simulations, flight behind an icing tanker, and, ultimately, flight into natural icing conditions. With the exponential increase in computer power and the accompanying sophistication of numerical technologies, computational fluid dynamics (CFD) is playing a rapidly growing, if not primary, role in the aero-icing certification process. Given the large number of icing conditions to be tested the use of wind/icing tunnels is slowly waning, as the full geometry (airplane, with engines running) cannot be tested, nor the altitude conditions easily replicated. Natural flight tests are the ultimate step to be completed before obtaining certification, and can sometimes be as short as one week [6]. Similarly, 3-D viscous turbulent CFDicing simulations of complete or even partial aircraft geometries are considered expensive and even prohibitive for parametric studies where the cost of repeated calculations could become overwhelming.

In addition, the current implementation of icing effects in flight training simulators is, in the view of experts and pilots, rather primitive and based on limited flight test data supplied by manufacturers, vide [6]. Since only limited aircraft flight data in icing conditions is available, and data from accidents can only be input a posteriori, icing effects in flight simulators are simply represented by a combination of increased weight, a displacement of the center of gravity and engine vibration. This rather primitive simulation may give pilots false impressions that are far from the 
realities of an actual icing encounter [3]. It goes without saying that if icing effects were to be represented with more fidelity in flight simulators, pilots could be better trained to recognize and recover, within the few seconds available to them, from the degraded handling qualities of an iced aircraft caused by ice accretion [7]. This ought to have a considerable beneficial impact on aviation safety, as the simulators of tomorrow have to be proactive and not reactive, preventing an accident from occurring rather than from repeating.

In the field of icing certification, replete with gross approximations, CFD-Icing tools are capable of providing more detailed, reliable and repeatable information about the "deltas" in aerodynamic degradation, for lift, drag and moments. However, generating large amount of CFD data corresponding to a wide range of pilot inputs e.g. pitch angle, indicated air speed (IAS), flight altitude, etc. requires a tremendous amount of computational resources, making it extremely difficult. For simulators, data is needed in real time, making the use of anything but lookup tables, impossible. Overcoming these two hurdles, namely a complete coverage of the icing envelopes, and obtaining 3-D complete aircraft simulation in real time, is the subject of the present paper, with a particular emphasis on the words complete and real time.

As a first step, and to reduce the computational complexity of covering the entire icing envelopes, a numerical simulator is proposed via reduced-order modeling (ROM), providing solutions of as great accuracy and as much detail as 3-D Navier-Stokes [8, 9]. The ROM approach uses a limited, but strategically selected, number of snapshots (defined at different flight and icing conditions) of the complex system to extract a basis of vectors (or modes) that represent its most relevant physical features. A linear combination of these modes can then be used to extremely rapidly obtain reduced-order solutions of great richness in features and details, for any other flight and icing conditions bounded by the ones from which the snapshots are defined. Different techniques can be adopted to compute the reduced-order basis vectors [10], the most used being proper orthogonal decomposition (POD) [11, 12]. Global or local POD methods can be used to identify the basis vectors for computing the reduced-order solutions. The global POD approach uses all the available snapshots to generate the basis. This method is straightforward, but for problems with locally distinct physical characteristics, e.g. glaze and rime ice formations in the case of aero-icing, or subsonic, supersonic and hypersonic regimes in the case of aerodynamic studies, solutions obtained by global POD may be affected by very different snapshots features. Local POD, on the other hand, deals with distinct physical characteristics separately. The local approach calls for the subdivision of the solution (and parameter) spaces into subregions, each 
ideally comprising snapshots characterized by similar or sufficiently close physical features. In the recent literature, $k$-means clustering has often been used for grouping similar snapshots into clusters [13, 14].

Once the basis vectors are determined, the scalar coefficients in the linear combination of modes can be obtained by using projection-based approaches $[15,16]$ or response surface methods $[8,9,17-21]$. The projection-based approaches require manipulation of governing equations of the problem that is not always well defined or compatible with the snapshots available, such as when the numerical snapshots are mixed with ones obtained from flight and/or experimental tests. Response surface methods, on the other hand, do not require dealing with the governing equations, and can therefore work with any combination of snapshots coming from CFD, experiments and/or flight tests data. Moreover, defining a response surface for each coefficient of the linear expansion is much more cost-effective than solving a system of ordinary differential equations required by a projection-based approach. Obtaining real-time data is thus more straightforward with response surface methods. The response surface for the mode coefficients can be obtained by polynomial [19], Akima or Kriging interpolations [8, 17, 18], or by radial basis functions [20, 21].

A crucial aspect in the success of a ROM approach is to optimally define the snapshots that best extract the physical features of the solution. In [22-25], a greedy sampling algorithm was introduced to adaptively place a new sample point at the location in the parameter space where the maximum error occurs. These techniques are developed in the community of projection-based model order reduction, rely on residual-based error bounds or error indicators to assess the accuracy of ROM solutions, and the location of new samples is determined either by a direct search [22, 23] or by an optimization algorithm $[24,25]$. In case formal error indicators are not available or difficult to define, the degree of accuracy of reduced-order solutions can be estimated via leave-one-out cross-validation (LOOCV): an approach compatible with mixed-type snapshots. Sampling techniques based on centroidal Voronoi tessellations (CVT) [26] could be employed in conjunction with LOOCV to identify the location of the snapshots in the parameter space according to a prescribed density function. As the density function for CVT can be based on either errors in the parameter space or a priori knowledge of the physics of the problem, it has the capacity to provide additional sample points judiciously placed in regions of high nonlinearity. Other approaches such as Latin Hypercube, $L p-\tau$ are straightforward, but are not amenable to error-driven iterative sampling [27, 28].

This article extends validation of the ROM 2-D framework presented in the previous paper [9] to the complete exploration of the FAA continuous maximum (CM) icing envelope for a regional jet (RJ). Machine learning algorithms $[29,30]$ are used to address the clustering of snapshots and delimit ice-type regions within the envelope. For 
aerodynamic degradations resulting from airframe ice accumulation, detailed parametric analysis is performed on varied flight conditions. The greedy algorithm and CVT are combined in an iterative framework to position snapshots in the regions of high nonlinearity, determining a judicious balance between accuracy and number of snapshots.

The paper is organized as follows: section 2 briefly reviews the method of reduced-order modeling and its localization, as well as iterative sampling approach. Section 3 demonstrates the proposed methodologies for the exploration of appendix C CM icing envelope on a regional jet. Section 4 presents the aerodynamic performance degradation analysis of an ice-contaminated airplane. Finally, in section 5, some conclusions are given.

\section{Methodologies}

The local ROM and iterative sampling framework presented in [9] is adopted and extended in the present work, with only a brief summary given here. The CFD-icing tools used in this paper are also briefly described at the end of this section.

\section{A. The Method of Reduced-Order Modeling}

For an ensemble of $N_{S}$ observations $\left\{\boldsymbol{U}_{1}, \ldots, \boldsymbol{U}_{N_{S}}\right\}$, where $\boldsymbol{U}_{i}=\boldsymbol{U}\left(\mathbf{x}_{i}\right) \in \mathbb{R}^{N_{P}}$, and $\mathbf{x}_{i} \in \mathbb{R}^{N_{D}}$ specifies input parameters defining observation conditions. For icing analysis, $\boldsymbol{U}$ may be ice thickness at the $N_{P}$ surface nodes, while $\mathbf{x}$ defines icing condition in terms of MVD, LWC, etc.; for aerodynamic analysis, $\boldsymbol{U}$ can be the solution field of interest, e.g. pressure and shear stress, while $\mathbf{x}$ defines flight conditions like angle of attack (AoA), speed, flight altitude, etc. POD yields a set of basis vectors $\boldsymbol{\varphi}_{j} \in \mathbb{R}^{N_{P}}, j=1, \ldots, N_{S}$ that best represents the dominant physical behavior featured within the snapshots. An "untried" solution of the system can be approximated via a linear combination of the modes

$$
\boldsymbol{V}=\sum_{j=1}^{M<N_{S}} \alpha_{j}^{\delta} \boldsymbol{\varphi}_{j}
$$

where $M$ indicates the truncation of the expansion at the desired level of energy content associated with each mode.

For each mode $\boldsymbol{\varphi}_{j}$, the projection coefficient at each snapshot location $\mathbf{x}_{i}$ can be expressed as

$$
\alpha_{j}^{i}=\boldsymbol{U}_{i} \cdot \boldsymbol{\varphi}_{j}
$$

The $\alpha_{j}^{i}, i=1, \ldots N_{S}$ form a multidimensional response surface for each mode $\boldsymbol{\varphi}_{j}$, having as input the parameters $\mathbf{x}_{i}$ of the analysis and as outputs the $\alpha_{j}^{i}$ coefficients. Then for any untried input parameter $\mathbf{x}_{\delta}$, the mode coefficient $\alpha_{j}^{\delta}$ can be obtained from Kriging interpolation. 
Kriging interpolation requires the maximization of the likelihood function [31], for which the analytical formula is known, but the shape of the function might become highly nonlinear and present multiple optima, as the problem and/or the snapshots change. A Genetic Algorithm (GA) driver (http://www.cuaerospace.com/Technology) was selected due to its robustness in identifying the global optimum (as opposed to local optimum), even with complex and highly nonlinear objective functions. A drawback of this approach is that it takes a relatively long time to locate the exact local optimum. Therefore, in this work, a gradient-based quasi-Newton line search method [32] was developed and combined with the GA driver to speed up the search for a global optimum.

\section{B. Localization via Machine Learning}

To build local reduced models, three issues have to be addressed. First, similar snapshots are grouped into clusters and POD is then locally applied to each cluster to generate a local set of basis vectors. Secondly, identify the most suitable cluster for the new solution of an untried condition to be represented as a linear combination of the POD basis of only that cluster. Last but not least, define the boundaries of the subregions in the parameter space such that each cluster is ideally enclosed, leaving no void regions in the parameter space.

The desired clustering can be achieved by using an unsupervised learning algorithm known as $k$-means clustering, also adopted in $[13,14]$. In this context the snapshots $\left\{\boldsymbol{U}_{1}, \ldots, \boldsymbol{U}_{N_{S}}\right\}$ are taken as input, and the desired output is the class label $\mathcal{C}_{k} \in \mathbb{Z}, k=1, \ldots, K$, which identifies a snapshot with a cluster $k$. The identification of the proper cluster for an untried condition $\mathbf{x}_{\delta} \in \mathbb{R}^{N_{D}}$, and the definition of the boundaries of each cluster in the parameter space are classification problems that fall into the category of supervised learning, for which the method of logistic regression

was selected. To assign an input vector $\mathbf{x}_{i} \in \mathbb{R}^{N_{D}}$ to one among $K$ available classes $\mathcal{C}_{k}, k=1, \ldots, K$, a classifier is trained using a training set $S=\left\{\left(\mathbf{x}_{1}, t_{1}\right), \ldots,\left(\mathbf{x}_{N_{S}}, t_{N_{S}}\right)\right\}$, where $t \in \mathbb{Z}$ is the label of the class. Since the classes are disjoint sets, the input space can always be divided into decision regions, with boundaries identified as decision boundaries. Brief summary of these two methods can be found in [9].

\section{Iterative Sampling and Leave-One-Out Error Evaluation}

Identifying the best number and location of snapshots in the parameter space is a non-trivial task. Since it is not known a priori how many snapshots to compute and/or which operating conditions are the most important to consider, an iterative sampling strategy based on a "greedy" application of centroidal Voronoi tessellation (CVT) is proposed, where an initial ensemble of snapshots is iteratively optimized according to a prescribed error estimation procedure. 
The CVT-based iterative sampling is somewhat analogous to greedy approaches [25, 33-35], in terms of placing points where the error is high but differs in the way the error is computed. While greedy approaches rely on residual-based error bounds and error indicators, in this paper, a more heuristic, but conclusive, leave-one-out cross-validation (LOOCV) error has been selected to guide the proposed iterative sampling process. The error estimator of the ROM prediction is obtained by comparing the ROM solution with the corresponding high fidelity CFD solution (snapshot) via a LOOCV approach $[29,30]$. Given a set of $N_{S}$ snapshots, one of the snapshots is excluded from the set and adopted as a reference solution (i.e. CFD solution), then the reduced-order model is defined on the basis of the other $N_{s}-1$ snapshots by which a reduced-order solution (i.e. ROM solution) can be obtained for the conditions of the selected reference solution and eventually compared with the reference one. In order to have an indication over the entire parameter space of the analysis, this approach is used $N_{s}$ times, excluding at each time a different snapshot. A flowchart illustrating the error driven sampling and LOOCV is given in Fig. 1. In the context of local ROM the iterative sampling and cross-validation are performed separately on each cluster of snapshots.

\section{CFD-Icing Tools}

All CFD-aero and CFD-icing snapshots adopted in this paper are obtained using FENSAP-ICE simulation system [36], which includes modules for Navier-Stokes flow prediction, water droplet impingement computation by an Eulerian method, prediction of the 3-D ice accretion/water runback, and conjugate heat transfer for anti-icing and deicing, all based on partial differential equations for viscous turbulent flows, and in three dimensions [37-39]. For complex geometries, the mesh can be optimized by OptiGrid [40]. Validation of FENSAP-ICE and OptiGrid is beyond the scope of this paper and has been extensively covered in other articles [37-40].

For the simulation of ice accretion for a certain period of time, the FENSAP-ICE system can be configured as oneshot, multi-shot or unsteady icing calculations, as illustrated in Fig. 2 [41]. In this interactive loop, each module (airflow, impingement, accretion) are solved independently, with selected variables passed between them. At the end of each iteration, a displaced grid accommodating accreted shape of ice is generated. This grid will be used by the flow solver for the next iteration.

\section{Exploration of the Continuous Maximum Icing Envelope}

The proposed local reduced-order modeling, coupled with the iterative sampling methodology, are applied to the problem of in-flight icing certification, to estimate ice buildup on unprotected aircraft surfaces during a holding pattern 
in a 17.4 nautical miles region of the $\mathrm{CM}$ icing conditions (Fig. 3 left). A RJ (Fig. 3 right) with a $2.93 \mathrm{~m} \mathrm{mean}$ aerodynamic chord and $27.28 \mathrm{~m}$ span has been considered in this work. Airspeeds and altitudes have been selected to represent a typical holding condition, e.g. pressure altitude of 5,000 meters with a true air speed of 268 knots at an AoA of $3.7^{\circ}$. The exposure time considered is 25 minutes, a preliminary exploration for the maximum 45 -min hold certification requirement. The purpose is to demonstrate that ice shapes and mass within the CM icing envelope can be "completely" explored via ROM, not only for sections of the wing but for the entire aircraft. Namely, based on the set of pre-computed ice shapes snapshots, one can obtain the shapes and mass of ice "everywhere" inside the icing envelope.

A hybrid mesh of 9,788,214 nodes, 14,926,688 prism elements and 12,587,875 tetrahedral elements is used by FENSAP-ICE to provide the necessary CFD-aero and CFD-icing snapshots. Ice accretion was done as a one-shot 25minute accretion, with the availability of multi-shot or truly unsteady ice accretion when and if more precision is needed. For the analysis of ice shapes, the snapshots, $\boldsymbol{U}_{i}$, are the Cartesian coordinates of the 202,260 nodes defining the surface mesh. As a result of ice accretion, the surface mesh is displaced from the original clean surface. The accuracy of the ROM predictions versus CFD results is evaluated via the LOOCV. For each snapshot $\boldsymbol{U}_{i}$, the vector of the errors $\varepsilon_{j}^{i}$ at each node $j$ of the surface mesh is defined as the difference of ice thickness $\delta_{j}^{i}$ at that mesh point, namely

$$
\varepsilon_{j}^{i}=\left|\delta_{j, R O M}^{i}-\delta_{j, C F D}^{i}\right|, i=1, \ldots, N_{S}, j=1, \ldots, N_{P}
$$

Then for any location $i$ in the parameter space, the LOOCV error is expressed as the mean square root of the error vector

$$
\varepsilon_{i c e}^{i}=\sqrt{\frac{\sum_{j=1}^{N_{P}}\left(\varepsilon_{j}^{i}\right)^{2}}{N_{P, \text { iced }}}}, i=1, \ldots, N_{S}, j=1, \ldots, N_{P}
$$

where $N_{P, \text { iced }}$ is the number of surface nodes displaced due to ice accretion. These errors were used to define the density function in CVT for the subsequent sampling iteration, which identifies new samples/snapshots to be added in the high error region.

In our previous work - exploration of icing envelopes on a 2-D airfoil [9] - we showed that there exist three typical types of ice snapshots within the CM: no ice (clean geometry) or trace ice (ice becomes perceptible), glaze/mixed ice and rime ice. These different types of solutions could numerically pollute each other in the context of ROM, an expected result of using global POD for highly nonlinear problems. Local ROM is therefore introduced to handle these 
distinct solutions separately by subdividing the icing envelope into three sub-regions. In this work, local ROM is validated on a 3-D geometry; detailed analysis will be given in the remainder of this section.

\section{A. Initial Sampling and LOOCV}

The initial sampling consists of 36 points (Fig. 3 left), each representing a different icing condition in terms of MVD, LWC and, implicitly, external temperature. Figure 4 illustrate examples of typical snapshots, representing glaze ice, rime ice and trace ice, respectively. These figures demonstrate ice thickness contours obtained for the specific icing condition, as well as ice shape comparisons of ROM solution versus CFD solution at different sections of the airplane, during LOOCV at this specific snapshot location, i.e. the ROM solution is obtained based on the remaining 35 snapshots. In this analysis, an energy content of $99.9999 \%$ is selected heuristically, corresponding to 26 modes for $x$ coordinate, 28 modes for $y$ coordinate, and 25 modes for the $z$ coordinate used in ice shape prediction.

Figure 5 (left) shows the LOOCV error distribution associated with the initial set of snapshots (the LOOCV errors at each snapshot location are interpolated to obtain error estimation everywhere in the parameter space). The highest error in terms of ice thickness is $4.4 \mathrm{~mm}$ (which accounts for $15 \%$ of $\delta_{\text {ice,CFD,max }}$ ). These errors were used to define the density function of CVT for the subsequent iteration of sampling, which identifies new samples/snapshots to be added in the high error region.

\section{B. Error Driven Sampling and Local ROM}

The experience obtained from the 2-D analysis [9] suggests that an adequate number of snapshots should be collected before subdividing of the parameter space. Since no a priori knowledge regarding where the most critical region (glaze/mixed ice) would be located within the envelope, it is preferable to start from a smaller number of uniformly distributed snapshots, and iteratively enrich them according to a suitable error indicator. Figure 5 (right) shows the snapshots and clustering after 6 sampling iterations, with 80 snapshots.

The clustering analysis was done based on ice thickness over the airplane. The 80 snapshots are grouped into three subsets: no-ice or trace ice (cluster 1), glaze/mixed ice (cluster 2) and rime ice (cluster 3). The decision boundaries between clusters are determined via logistic regression, using a degree-4 polynomial feature mapping with a regularization factor of 0.0001 , as shown in Fig. 5 (right). Before doing the leave-one-out error evaluation for each cluster, the snapshots on the decision boundaries need to be computed such that each cluster is totally enclosed. Therefore ten points were defined on the decision boundary between clusters 1 and 2, and six points were defined on 
the decision boundary between clusters 2 and 3 . These corresponding snapshots were shared between the neighboring subregions, leaving no untagged areas in the parameter space.

Once the boundaries are established, error driven sampling is continued on each cluster. At the end of the iterative sampling, 103 snapshots are obtained, partitioned into 3 clusters, for a final state of three local reduced-order bases. Figure 6 (left) shows the ice thickness error distribution for the last iteration. The maximum error has been reduced to $2.7 \mathrm{~mm}$ (which accounts for $9 \%$ of $\delta_{\text {ice,CFD, } \max }$ ), a $40 \%$ deduction of the maximum error obtained from the initial sampling, whereas for the majority of the icing envelope, the error is less than $1.2 \mathrm{~mm}$.

\section{Complete Exploration of the CM}

With the displaced surface mesh, the volume of accreted ice can be determined by calculating the volume of the space enclosed by the iced surface and the clean geometry. TetGen [42] is adopted to fill this space with a tetrahedral mesh, from which the total volume can be directly calculated. Mass of ice can then be determined by multiplying the volume with ice density $\left(917 \mathrm{~kg} / \mathrm{m}^{3}\right)$. Figure 6 (right) illustrates the overall mass of ice accumulation throughout the $\mathrm{CM}$ icing envelope. This result is obtained from 1,000 ROM solutions, which are uniformly distributed in the parameter space. Each target condition is sorted into a corresponding cluster by the classifier trained via logistic regression. Then, the specific reduced-order basis from that cluster is used to build the reduced solution.

The computational cost of the proposed local ROM can be split into off-line and on-line costs, as shown in Table 1. The collection/computation of snapshots, the adaptive sampling and training of local reduced-order models can be considered as the off-line, or major, cost. For a new target, the on-line cost consists only in the identification of the corresponding local reduced-order basis and interpolation of mode coefficients. In the current test case for a complete aircraft, the computational time of each CFD-ICE is 16 to 32 hours using 128 CPUs, and is the off-line cost. The online cost of computing each ROM solution takes 1.4 seconds using 6 CPUs. As shown in Fig. 6 (right), the accumulated mass of ice can reach a maximum of 142 kilograms, mainly in the region where total temperature is close to the freezing point and large amounts of liquid water are conducive to the formation of larger amount of ice. This mass of ice distribution could be helpful for rapidly and accurately determine the critical mass in the design of ice protection systems and thus manage optimum energy requirements for all icing conditions. 


\section{Aerodynamic Degradations for Ice Contaminated Aircraft}

After holding in $\mathrm{CM}$ icing conditions for a certain time, ice buildup will adversely affect aerodynamic performance. It is important to reassess performance during the subsequent descent, and even more critically for an aborted landing, for which pilots need to rapidly pull up and climb to a newly assigned altitude, afterwards, either prepare for re-landing, or divert to an alternate airport.

The purpose of this section is to demonstrate that, based on a set of pre-computed flow solutions under various flight conditions taken as snapshots, flow details in terms of pressure distribution and shear stress distribution (which are the major sources of lift and drag) for any untried flight condition can be obtained via ROM. In this work, the focus is on the analysis of steady longitudinal flight performance of a regional jet. The resultant data can be incorporated into flight simulators, enabling icing scenario training for the pilots to better understand the hazards of in-flight icing, particularly in holding, descent or aborted landing.

The ice shape considered is obtained by FENSAP-ICE from a 45-minute exposure under a CM icing condition $\left(\mathrm{MVD}=21.26 \mu \mathrm{m}, \mathrm{LWC}=0.30 \mathrm{~g} / \mathrm{m}^{3}\right)$, at typical holding flight conditions $(5,000$ meters pressure altitude, 268 knots true air speed and $3.675^{\circ} \mathrm{AoA}$ ), with clean aircraft configuration (flaps/slats retracted, no deflection of control surfaces). A hybrid mesh with 9,788,214 nodes, 14,926,688 prism elements and 12,587,875 tetrahedral elements is considered. For the aerodynamic analysis in question, the snapshots $\boldsymbol{U}_{i}$ are the flow variables of interest: pressure at the $9,788,214$ nodes of the volume mesh and shear stress at the 202,260 surface nodes.

\section{A. Parameters of the Analysis and Iterative Sampling}

For the steady flight analysis and flight performance of a RJ in descent, climb and level flights, three parameters are selected: indicated airspeed (IAS), AoA and pressure altitude (PA). These three parameters are typical inputs made by pilots for longitudinal operation of the aircraft (AoA is equivalent to pitch angle minus flight path angle). Besides these three parameters, atmospheric parameters such as static pressure, static temperature and density are also required for setting up the numerical simulations. The International Standard Atmosphere model [43] is adopted to determine how atmospheric parameters change over the range of flight altitudes. The parameters range covered in the present analysis is shown in Table 2 .

The initial sampling consists of 84 points (Fig. 7), with 64 inside the design space and 20 on the boundaries. Error is estimated on the basis of a leave-one-out approach: for any location $i$ in the parameter space where a snapshot $\boldsymbol{U}_{i}$ is 
available, the error can be computed as the normalized $\mathrm{L}_{2}$-norm of the vector of the errors $\varepsilon_{j}^{i}$ at each node $j$ of the mesh

$$
\varepsilon_{j}^{i}=\left\|U_{j, R O M}^{i}-U_{j, C F D}^{i}\right\|_{2} /\left\|U_{j, C F D}^{i}\right\|_{2}, i=1, \cdots, N_{S}, j=1, \cdots, N_{P}
$$

For pressure field, $U_{j}^{i}=p_{j}^{i}$ is the pressure value at node $j$ of snapshot $i$; for shear stress field, $U_{j}^{i}=\tau_{j}^{i}=$ $\sqrt{\left(\tau_{j, x}^{i}\right)^{2}+\left(\tau_{j, y}^{i}\right)^{2}+\left(\tau_{j, z}^{i}\right)^{2}}$ is the magnitude of shear stress at node $j$ of snapshot $i$. Then the volume weighted overall error at each location $i$ in the parameter space can be expressed as

$$
\varepsilon^{i}=\sqrt{\sum_{j=1}^{N_{P}}\left(\varepsilon_{j}^{i} v_{j}\right) / \sum_{j=1}^{N_{P}} v_{j}, i}=1, \cdots, N_{S}, j=1, \cdots, N_{P}
$$

where $v_{j}$ is the cell volume of each node of the mesh.

Figure 8 shows the LOOCV volume weighted $\mathrm{L}_{2}$-norm error of pressure field and shear stress field, over the ice contaminated aircraft. The LOOCV errors at each snapshot location are interpolated to obtain error estimation everywhere in the parameter space. As can be seen, the highest error of pressure and shear stress are $1.5 \%$ and $8.6 \%$, respectively. Given that the pressure field accuracy is fairly good, the error driven sampling is focused on shear stress only. After seven sampling iterations, 129 snapshots were defined (Fig. 9), with LOOCV error reduced to $1.3 \%$ and $6.0 \%$, for pressure and shear stress, respectively. For the present demonstration, a maximum error of $6.0 \%$ is considered satisfactory and no further snapshots are added to the set of CFD solutions.

In order to assess the aerodynamic performance degradation, flow solutions over the clean geometry are needed and 129 such snapshots under the same flight conditions as the ice-contaminated aircraft have been computed. The LOOCV of clean solutions are shown in Fig. 10. The highest error of pressure and shear stress are 1.0\% and 11.9\%, respectively. Although higher than the ice-contaminated case, this level of accuracy can be considered acceptable.

\section{B. Aerodynamic Analysis for an Aborted Landing}

Based on these two sets of snapshots (129 CFD solutions each, clean and iced) and the estimated error, one is reasonably confident to make predictions for other flight conditions within the parameter space. A hypothetical flight path representing an aborted descent is simulated using 21 target points, as shown in Fig. 11. The parameter values of points on the flight path are selected to be as close to a realistic flight operation as possible. Among these 21 flight conditions, targets 1 to 9 represent the process that the airplane is allowed to exit holding pattern and descend to 3,000 
feet; targets 9 to 13 demonstrate the abortion of the descend, where the AoA increases from $0.9^{\circ}$ to $7.0^{\circ}$, and the airplane starts to regain altitude; targets 13 to 21 illustrate the climb stage, for which the aircraft gets back to the holding altitude and resume level flight AoA, after which it may need to prepare for a second landing, or fly to an alternate airport. The input parameter values of targets 1, 9, 13 and 21 are listed in Table 3.

Based on the two sets of 129 snapshots each, 21 ROM solutions for the ice-contaminated airplane and another 21 ROM solutions for the clean airplane are obtained. As a validation, CFD solutions for flight conditions 1, 9, 13 and 21 , on both iced and clean geometries, are computed to check the accuracy of ROM solutions. The volume weighted $\mathrm{L}_{2}$-norm error of field variable in terms of pressure and shear stress are summarized in Table 4. As one can see, all errors are well bounded by the LOOCV error estimators; therefore the leave-one-out approach provides reliable error estimation.

Figure 12 gives detailed comparison of ROM vs. CFD results in terms of field quantities (pressure and shear stress) over the ice contaminated airplane, under target flight condition 13, which is located at the bottom of descent, where the airplane just re-establishes a climbing altitude (IAS $=200 \mathrm{kt}, \mathrm{AoA}=7.0^{\circ}, \mathrm{PA}=4,300 \mathrm{ft}$ ). To ensure an energy content of $99.999 \%, 18$ modes for pressure field, 98, 96 and 77 modes for shear stress in the $\mathrm{x}, \mathrm{y}, \mathrm{z}$ directions were used in field variable prediction. Three cross-sections over the wing $(21.6 \%, 50.1 \%$ and $95.2 \%$ of wing span) and one cross-section of tail (56.3\% tail span) are selected. As illustrated, ROM solution agrees very well with CFD solutions. Figure 13 shows comparison of ROM vs. CFD on pressure and shear stress, at the same target flight condition 13, but over the clean airplane. Again, the ROM solution agrees well with the CFD solutions for most parts of the wing and tail. Figure 14 and Fig. 15 demonstrate flow field comparison under flight condition 21, which is at the top of the climb path (IAS $=265 \mathrm{kt}, \mathrm{AoA}=3.675^{\circ}, \mathrm{PA}=15,000 \mathrm{ft}$ ), for ice contaminated and clean geometries, respectively. The off-line and on-line costs as summarized in Table 5. In this test case, the computational time of each CFD flow solution is 24 hours on 128 CPUs (off-line cost). With these CFD solutions taken as snapshots, building a reduced model database (extracting POD modes, solving Kriging model parameters) takes 36.8 min on 16 CPUs (off-line cost). Once this database is stored, solving a ROM solution containing pressure and shear stress fields only takes 28 seconds using 16 CPUs (on-line cost).

\section{Performance Degradation: Icing Encounters Flight Simulator}


Figure 12-15 demonstrate the accuracy of ROM in terms of field variables. Since ROM solution contains information on all grid points, it is possible to integrate the pressure field to obtain the lift coefficient, and integrate shear stress to get the drag coefficient. Although at some sections of the wing ROM and CFD do not perfectly match, after integration, the lift coefficient $\left(C_{L}\right)$, drag coefficient $\left(C_{D}\right)$ and pitching moment $\left(C_{M}\right)$ have a very small error, as shown in Table 6.

It is of interest to see how performance is penalized during this aborted descent due to ice accretion. Moreover, what is important in a flight simulator are not the exact values but the differences in lift, drag and moments, which can be very accurate with the present method. Figure 16 illustrates aerodynamic degradation in terms of lift, drag and pitching moment for the ice contaminated airplane, while Fig. 17 gives aerodynamic penalty in percentage. As can be seen, the increase of drag due to ice accretion is significant, reaching as much as $61 \%$, compared to the clean aircraft. Meanwhile, lift may decrease up to $17 \%$, and the change of pitching moment is as high as $20 \%$. The reason for relatively low penalty on lift is that the ice shape is rime $\left(\mathrm{MVD}=21.26 \mu \mathrm{m}, \mathrm{LWC}=0.30 \mathrm{~g} / \mathrm{m}^{3}\right.$, Temperature $=-13.4$ ${ }^{\circ} \mathrm{C}$ ). Such aerodynamic degradation values, easily speeded up to real time (about $1 / 15^{\text {th }}$ of a second) by using GPUs, can be incorporated into flight simulators, with additional CFD-based visual aids, making pilots training correspond to real time and real life by greatly improving simulator fidelity. Moreover, although the present analysis covers prestall AoAs, it can be easily extended to stall and post stall range of AoAs, therefore to enable stall recognizing and recovery training.

\section{Conclusions}

The paper presents a rigorous and self-contained ROM framework based on proper orthogonal decomposition, multi-dimensional interpolation and machine learning algorithms, along with an error driven iterative sampling to adaptively reach an optimal set of snapshots. The methodology is applied, it is believed for the first time, to a detailed study of the aero-icing of a regional jet, in terms of: 1) the "complete" exploration of the FAA CM icing conditions for the shape/mass of ice, and 2) its aerodynamic degradation due to ice contamination during holding, and the consequent effect during descent and aborted landing.

These examples, even though quite meaty, are only meant as illustrations of a technology that signals a paradigm shift in certification by greatly enriching the data presented to airworthiness authorities for certifying an aircraft to fly into known icing. The methodology is comprehensive in permitting the combination of CFD, experimental fluid 
dynamics (EFD), and flight fluid dynamics (FFD). A numerical simulator can be built at the time of preliminary design, allowing the estimation of the effect of design changes on the ice resistance of the aircraft. It can also be used to make the simulator a proactive tool in preventing accidents rather than just their reoccurrence. In addition, while the icing certification envelope is the same for all aircraft, its effect on each class of aircraft is far from being the same. Yet, most natural icing tests are guided by meteorologists who have a profound knowledge of the atmosphere but are not necessarily equipped to evaluate the relevance of a particular icing cloud data point to a specific aircraft. Thus, the current methodology can be used to assess the significance of an icing encounter before launching the aircraft into it, and also to give confidence to the pilots as to the anticipated behavior of the aircraft. Its applications to ice shape testing during a certification or a supplemental type certification is also powerful in terms of predicting 3-D ice shapes and assessing how to incrementally add these shapes to the aircraft in order to guarantee the safety of pilots.

Thus, in summary, the technology enables designers to avoid any "blind spots" and provides data for conditions that could not be located in nature, or that are too dangerous or impossible to test in real life. Although in this work,

only CFD data is used as the snapshots for ROM, it should be pointed out that the proposed methodology is comprehensive in permitting a combined CFD-EFD-FFD database. In such case, certification will not only be more complete, and dangerous areas fully identified, but in addition certification campaigns could be shortened to one season instead of several. As for flight simulators, it can be used to make the simulator a proactive tool in preventing accidents rather than just their reoccurrence. All these will lead to beneficial and sustained impact on aviation safety through CFD simulations.

\section{Acknowledgments}

The authors would like to thank the Natural Sciences and Engineering Research Council of Canada for funding through a Discovery Grant. We are also grateful to Compute Canada and CLUMEQ for the use of their supercomputer resources.

\section{References}

[1] Dillingham, G. L., "Aviation Safety: Improved Planning Could Help FAA Address Challenges Related to Winter Weather Operations," United States Government Accountability Office, GAO-10-678, 2010. 
[2] Dillingham, G. L., "Aviation Safety: Icing and Winter Weather-Related Recommendations That NTSB Has Issued Since 1996 (GAO-10-679SP), an E-supplement to (GAO-10-678)," United States Government Accountability Office, GAO-10-679SP, 2010.

[3] "Aircraft Accident Report: Crash During Approach to Landing, Empire Airlines Flight 8284, Avions de Transport Régional Aérospatiale Alenia ATR 42-320, N902FX, Lubbock, Texas, January 27, 2009," National Transportation Safety Board, NTSB/AAR-11/02, 2011.

[4] Code of Federal Regulations, Title 14 - Aeronautics and Space, Part 25 - Airworthiness Standards: Transport Category Airplanes, Federal Aviation Administration, Washington, D.C. 20591, revised and re-issued annually.

[5] "Airplane and Engine Certification Requirements in Supercooled Large Drop, Mixed Phase, and Ice Crystal Icing Conditions," Department of Transportation, Federal Aviation Administration, Notice of Proposed Rulemaking, FAA-2010-0636, Federal Register, Vol. 75, No. 124, 2010, pp. 37311-37339.

[6] Bernstein, B. C., Campo, W., Algodoal, L., Bottino, F., Lilie, L., and Henriques, A., "The Embraer-170 and -190 Natural Icing Flight Campaigns: Keys to Success," AIAA Paper 2006-264, Jan. 2006.

doi: $10.2514 / 6.2006-264$

[7] "Flight Simulation Training Device Qualification Standards for Extended Envelope and Adverse Weather Event Training Tasks," Department of Transportation, Federal Aviation Administration, Notice of Proposed Rulemaking, FAA-2014-0391, Federal Register, Vol. 79, No. 132, 2014, pp. 39462-39753.

[8] Fossati, M., and Habashi, W. G., "Multiparameter Analysis of Aero-Icing Problems Using Proper Orthogonal Decomposition and Multidimensional Interpolation," AIAA Journal, Vol. 51, No. 4, 2013, pp. 946-960. doi: $10.2514 / 1 . J 051877$

[9] Zhan, Z., Habashi, W. G., and Fossati, M., "Local Reduced-Order Modeling and Iterative Sampling for Parametric Analyses of Aero-Icing Problems," AIAA Journal, Vol. 53, No. 8, 2015, pp. 2174-2185. doi: $10.2514 / 1 . J 053654$

[10] Lucia, D. J., Beran, P. S., and Silva, W. A., "Reduced-Order Modeling: New Approaches for Computational Physics," Progress in Aerospace Sciences, Vol. 40, No. 1, 2004, pp. 51-117.

doi: 10.1016/j.paerosci.2003.12.001 
[11] Holmes, P., Lumley, J. L., and Berkooz, G., Turbulence, Coherent Structures, Dynamical Systems and Symmetry, Cambridge, U.K.: Cambridge University Press, 1996.

[12] Sirovich, L., "Turbulence and the Dynamics of Coherent Structures. Part I: Coherent Structures," Quarterly of Applied Mathematics, Vol. 45, 1987, pp. 561-571.

[13] Amsallem, D., Zahr, M. J., and Farhat, C., "Nonlinear Model Order Reduction Based on Local ReducedOrder Bases," International Journal for Numerical Methods in Engineering, Vol. 92, No. 10, 2012, pp. 891916.

doi: $10.1002 /$ nme.4371

[14] Peherstorfer, B., Butnaru, D., Willcox, K., and Bungartz, H. J., "Localized Discrete Empirical Interpolation Method," SIAM Journal on Scientific Computing, Vol. 36, No. 1, 2014, pp. A168-A192. doi: $10.1137 / 130924408$

[15] Lucia, D. J., and Beran, P. S., "Projection Methods for Reduced Order Models of Compressible Flows," Journal of Computational Physics, Vol. 188, No. 1, 2003, pp. 252-280.

doi: 10.1016/S0021-9991(03)00166-9

[16] Fang, F., Pain, C. C., Navon, I., Elsheikh, A., Du, J., and Xiao, D., "Non-Linear Petrov-Galerkin Methods for Reduced Order Hyperbolic Equations and Discontinuous Finite Element Methods," Journal of Computational Physics, Vol. 234, 2013, pp. 540-559.

doi: $10.1016 /$ j.jcp.2012.10.011

[17] Nakakita, K., Nadarajah, S., and Habashi, W., "Toward Real-Time Aero-Icing Simulation of Complete Aircraft via FENSAP-ICE," Journal of Aircraft, Vol. 47, No. 1, 2010, pp. 96-109.

doi: $10.2514 / 1.44077$

[18] Lappo, V., and Habashi, W. G., "Reduced Order POD/Kriging Modeling for Real-Time 3D CFD," $11^{\text {th }}$ Pan American Congress of Applied Mechanics, Foz do Iguaçu, PR, Jan. 2010.

[19] Bui-Thanh, T., Damodaran, M., and Willcox, K., "Proper Orthogonal Decomposition Extensions for Parametric Applications in Compressible Aerodynamics," AIAA Paper 2003-4213, June 2003.

[20] Mifsud, M. J., Shaw, S. T., and MacManus, D. G., "A High-Fidelity Low-Cost Aerodynamic Model Using Proper Orthogonal Decomposition," International Journal for Numerical Methods in Fluids, Vol. 63, No. 4, 2010, pp. 468-494. 
doi: 10.1002/fld.2085

[21] Xiao, D., Yang, P., Fang, F., Xiang, J., Pain, C., and Navon, I., "Non-Intrusive Reduced Order Modelling of Fluid-Structure Interactions," Computer Methods in Applied Mechanics and Engineering, Vol. 303, 2016, pp. 35-54.

doi: $10.1016 /$ j.cma.2015.12.029

[22] Veroy, K., and Patera, A. T., "Certified Real-Time Solution of the Parametrized Steady Incompressible Navier-Stokes Equations: Rigorous Reduced-Basis a Posteriori Error Bounds," International Journal for Numerical Methods in Fluids, Vol. 47, No. 8, 2005, pp. 773-788.

doi: $10.1002 /$ fld. 867

[23] Haasdonk, B., and Ohlberger, M., "Reduced Basis Method for Finite Volume Approximations of Parametrized Linear Evolution Equations," ESAIM: Mathematical Modelling and Numerical Analysis, Vol. 42, No. 2, 2008, pp. 277-302.

doi: 10.1051/m2an:2008001

[24] Bui-Thanh, T., Willcox, K., and Ghattas, O., "Model Reduction for Large-Scale Systems with HighDimensional Parametric Input Space," SIAM Journal on Scientific Computing, Vol. 30, No. 6, 2008, pp. 3270-3288.

doi: $10.1137 / 070694855$

[25] Paul-Dubois-Taine, A., and Amsallem, D., "An Adaptive and Efficient Greedy Procedure for the Optimal Training of Parametric Reduced-Order Models," International Journal for Numerical Methods in Engineering, Vol. 102, No. 5, 2015, pp. 1262-1292.

doi: $10.1002 / n m e .4759$

[26] Du, Q., Faber, V., and Gunzburger, M., "Centroidal Voronoi Tessellations: Applications and Algorithms," SIAM Review, Vol. 41, No. 4, 1999, pp. 637-676.

doi: $10.1137 / \mathrm{S} 0036144599352836$

[27] Sacks, J., Welch, W. J., Mitchell, T. J., and Wynn, H. P., "Design and Analysis of Computer Experiments," Statistical Science, Vol. 4, No. 4, 1989, pp. 409-423.

[28] Statnikov, R. B., and Matusov, J. B., Multicriteria Optimization and Engineering, Chapman and Hall New York, 1995, pp. 225-261. 
[29] Bishop, C. M., Pattern Recognition and Machine Learning, Springer, New York, 2006, Chaps. 1, 4, 9.

[30] Hastie, T., Tibshirani, R., and Friedman, J., The Elements of Statistical Learning, Springer, New York, 2009, Chaps. 4, 5, 7, 14 .

[31] Jones, D. R., "A Taxonomy of Global Optimization Methods Based on Response Surfaces," Journal of Global Optimization, Vol. 21, No. 4, 2001, pp. 345-383.

doi: 10.1023/A:1012771025575

[32] Dennis Jr, J. E., and Schnabel, R. B., Numerical Methods for Unconstrained Optimization and Nonlinear Equations, Vol. 16, Prentice-Hall, Englewood Cliffs, NJ, 1983.

[33] Veroy, K., Prud'homme, C., Rovas, D. V., and Patera, A. T., "A Posteriori Error Bounds for Reduced-Basis Approximation of Parametrized Non-Coercive and Nonlinear Elliptic Partial Differential Equations," AIAA Paper 2003-3847, June 2003.

doi: $10.2514 / 6.2003-3847$

[34] Bui-Thanh, T., Willcox, K., and Ghattas, O., "Parametric Reduced-Order Models for Probabilistic Analysis of Unsteady Aerodynamic Applications," AIAA Journal, Vol. 46, No. 10, 2008, pp. 2520-2529. doi: $10.2514 / 1.35850$

[35] Haasdonk, B., Dihlmann, M., and Ohlberger, M., "A Training Set and Multiple Bases Generation Approach for Parameterized Model Reduction Based on Adaptive Grids in Parameter Space," Mathematical and Computer Modelling of Dynamical Systems, Vol. 17, No. 4, 2011, pp. 423-442.

doi: $10.1080 / 13873954.2011 .547674$

[36] Habashi, W. G., "Recent Advances in CFD for In-Flight Icing Simulations," Japan Society of Fluid Mechanics, Vol. 28, No. 2, 2009, pp. 99-118.

[37] Baruzzi, G. S., Habashi, W. G., Guevremont, J. G., and Hafez, M. M., "A Second Order Finite Element Method for the Solution of the Transonic Euler and Navier-Stokes Equations," International Journal for Numerical Methods in Fluids, Vol. 20, No. 8-9, 1995, pp. 671-693.

doi: 10.1002/fld.1650200802

[38] Bourgault, Y., Boutanios, Z., and Habashi, W. G., "Three-Dimensional Eulerian Approach to Droplet Impingement Simulation using FENSAP-ICE, Part 1: Model, Algorithm, and Validation," Journal of Aircraft, Vol. 37, No. 1, 2000, pp. 95-103. 
doi: $10.2514 / 2.2566$

[39] Beaugendre, H., Morency, F., and Habashi, W. G., "FENSAP-ICE's Three-dimensional In-flight Ice Accretion Module: ICE3D," Journal of Aircraft, Vol. 40, No. 2, 2003, pp. 239-247.

[40] Habashi, W. G., Dompierre, J., Bourgault, Y., Fortin, M., and Vallet, M.-G., "Certifiable Computational Fluid Dynamics through Mesh Optimization," AIAA Journal, Vol. 36, No. 5, 1998, pp. 703-711. doi: $10.2514 / 2.458$

[41] "User Manual. FENSAP-ICE: FENSAP, DROP3D, ICE3D, C3D/CHT3D; OPTIGRID; FENSAP-FS," Newmerical Technologies International, Version 2013 Release 1.0, 2013.

[42] Si, H., "TetGen: A Quality Tetrahedral Mesh Generator and 3D Delaunay Triangulator," Weierstrass Institute for Applied Analysis and Stochastic, User's Manual, Version 1.5, 2013.

[43] "U.S. Standard Atmosphere," National Oceanic and Atmospheric Administration, 1976.

\section{List of Tables}

Table 1 Computational cost for CM exploration for the RJ

\begin{tabular}{c|c|c|c}
\hline \hline & \multicolumn{2}{|c|}{ Process } & Computational cost \\
\hline \multirow{4}{*}{ Off-line } & $\begin{array}{c}\text { CFD-icing } \\
\text { simulations }\end{array}$ & Each snapshot & $\begin{array}{c}16 \sim 32 \mathrm{~h} @ 128 \mathrm{CPUs} \\
\text { (depending on convergence } \\
\text { rate) }\end{array}$ \\
\cline { 2 - 4 } & $\begin{array}{c}\text { Iterative } \\
\text { sampling }\end{array}$ & $\begin{array}{c}\text { Each LOOCV; } \\
\text { each CVT sampling }\end{array}$ & $\begin{array}{c}1 \sim 2 \mathrm{~h} @ 6 \text { CPUs*; } \\
10 \sim 30 \mathrm{~s} @ \text { single CPUs }\end{array}$ \\
\cline { 2 - 4 } & $\begin{array}{c}\text { Machine } \\
\text { learning }\end{array}$ & $\begin{array}{c}k \text {-means clustering; logistic regression (defining } \\
\text { decision boundaries) }\end{array}$ & $\begin{array}{c}10 \sim 15 \text { seconds @ single } \\
\text { CPU** }\end{array}$ \\
\cline { 2 - 4 } On-line & $\begin{array}{c}\text { Build } \\
\text { database }\end{array}$ & $\begin{array}{c}\text { Extract POD modes from the final set of } \\
\text { snapshots; compute Kriging model parameter }\end{array}$ & 22 min @ 6 CPUs ${ }^{* *}$ \\
\hline \hline
\end{tabular}

* Intel Xeon E5-2670 eight-core (supercomputer Guillimin)

** AMD Phenom II X6 1075T Processor, 800 MHz (desktop computer)

Table 2 Flight conditions parameters, with their corresponding ranges

\begin{tabular}{cccccccc}
\hline \hline & IAS $[\mathrm{kt}]$ & AoA $\left.^{\circ}{ }^{\circ}\right]$ & $\mathrm{PA}[\mathrm{ft}]$ & $\mathrm{P}_{\text {static }}[\mathrm{Pa}]$ & $\mathrm{T}_{\text {static }}\left[{ }^{\circ} \mathrm{K}\right]$ & Density $\left[\mathrm{kg} / \mathrm{m}^{3}\right]$ & Mach \\
\hline Min & 190 & 0 & 3000 & 54900 & 256.47 & 0.75 & 0.30 \\
Max & 270 & 9 & 16000 & 90808 & 282.21 & 1.12 & 0.55 \\
\hline \hline
\end{tabular}

Table 3 Flight conditions parameters on Regional Jet flight path

\begin{tabular}{cccc}
\hline \hline & IAS [kt] & AoA [ $\left.{ }^{\circ}\right]$ & PA [ft] \\
\hline Target 1 & 255 & 3.675 & 15,000
\end{tabular}




\begin{tabular}{cccc} 
Target 9 & 195 & 0.9 & 4,000 \\
Target 13 & 200 & 7.0 & 4,300 \\
Target 21 & 265 & 3.675 & 15,000 \\
\hline
\end{tabular}

Table 4 Field variables' error of targets

\begin{tabular}{|c|c|c|c|c|}
\hline & \multicolumn{2}{|c|}{ Iced } & \multicolumn{2}{|c|}{ Clean } \\
\hline & $\left|P_{R O M}-P_{C F D}\right|$ & $\left|\tau_{R O M}-\tau_{C F D}\right|$ & $\left|P_{R O M}-P_{C F D}\right|$ & $\left|\tau_{R O M}-\tau_{C F D}\right|$ \\
\hline & $P_{C F D}$ & $\tau_{C F D}$ & $P_{C F D}$ & $\tau_{C F D}$ \\
\hline Target 1 & $6.4527 \mathrm{E}-04$ & $6.1656 \mathrm{E}-03$ & $6.1826 \mathrm{E}-04$ & $9.3841 \mathrm{E}-03$ \\
\hline Target 9 & $7.1029 \mathrm{E}-05$ & $6.8925 \mathrm{E}-03$ & $5.6252 \mathrm{E}-04$ & $2.6860 \mathrm{E}-02$ \\
\hline Target 13 & $2.2571 \mathrm{E}-04$ & $4.4945 \mathrm{E}-03$ & $2.3879 \mathrm{E}-04$ & 7.7051E-03 \\
\hline Target 21 & $1.5195 \mathrm{E}-04$ & $2.0054 \mathrm{E}-02$ & $3.8306 \mathrm{E}-04$ & 1.4939E-02 \\
\hline
\end{tabular}

Table 5 Computational cost of aerodynamic analysis for the RJ

\begin{tabular}{|c|c|c|c|}
\hline & \multicolumn{2}{|r|}{ Process } & \multirow{2}{*}{$\begin{array}{c}\text { Computational cost } \\
24 \mathrm{~h} @ 128 \mathrm{CPUs}^{*}\end{array}$} \\
\hline \multirow{3}{*}{ Off-line } & $\begin{array}{c}\text { CFD } \\
\text { simulations }\end{array}$ & Each snapshot & \\
\hline & $\begin{array}{l}\text { Iterative } \\
\text { sampling }\end{array}$ & $\begin{array}{c}\text { Each LOOCV; } \\
\text { each CVT sampling }\end{array}$ & $\begin{array}{c}\text { 6 27 h@16 CPUs }{ }^{*} \\
10 \sim 30 \mathrm{~s} @ \text { single CPUs }\end{array}$ \\
\hline & $\begin{array}{c}\text { Build } \\
\text { database }\end{array}$ & $\begin{array}{l}\text { Extract POD modes from the final set of } \\
\text { snapshots; compute Kriging model parameter }\end{array}$ & 36.8 min @16 CPUs* \\
\hline On-line & Solve target & $\begin{array}{l}\text { Logistic regression (classification); Linear } \\
\text { combination of POD modes }\end{array}$ & $28 \mathrm{~s} @ 16 \mathrm{CPUs}^{*}$ \\
\hline
\end{tabular}

* Intel Xeon E5-2670 eight-core (supercomputer Guillimin)

** AMD Phenom II X6 1075T Processor, 800 MHz (desktop computer)

Table 6 Integrated variables' error of targets

\begin{tabular}{cccc|ccc}
\hline & \multicolumn{3}{c|}{ Iced } & \multicolumn{3}{c}{ Clean } \\
\hline & $\frac{\Delta C_{L}}{C_{L, C F D}}$ & $\frac{\Delta C_{D}}{C_{D, C F D}}$ & $\frac{\Delta C_{M}}{C_{M, C F D}}$ & $\frac{\Delta C_{L}}{C_{L, C F D}}$ & $\frac{\Delta C_{D}}{C_{D, C F D}}$ & $\frac{\Delta C_{M}}{C_{M, C F D}}$ \\
\hline Target 1 & $2.78 \mathrm{E}-03$ & $2.19 \mathrm{E}-03$ & $3.02 \mathrm{E}-03$ & $4.76 \mathrm{E}-03$ & $9.85 \mathrm{E}-03$ & $4.55 \mathrm{E}-03$ \\
Target 9 & $1.67 \mathrm{E}-02$ & $1.66 \mathrm{E}-02$ & $2.11 \mathrm{E}-02$ & $9.03 \mathrm{E}-03$ & $4.42 \mathrm{E}-02$ & $1.48 \mathrm{E}-02$ \\
Target 13 & $1.27 \mathrm{E}-03$ & $6.74 \mathrm{E}-04$ & $1.06 \mathrm{E}-03$ & $1.06 \mathrm{E}-03$ & $3.51 \mathrm{E}-03$ & $1.22 \mathrm{E}-03$ \\
Target 21 & $9.58 \mathrm{E}-03$ & $9.16 \mathrm{E}-03$ & $1.08 \mathrm{E}-02$ & $4.33 \mathrm{E}-05$ & $7.64 \mathrm{E}-03$ & $2.61 \mathrm{E}-04$ \\
\hline \hline
\end{tabular}




\section{List of Figures}

Fig. 1 Flowchart of error driven iterative sampling (left) and LOOCV (right).

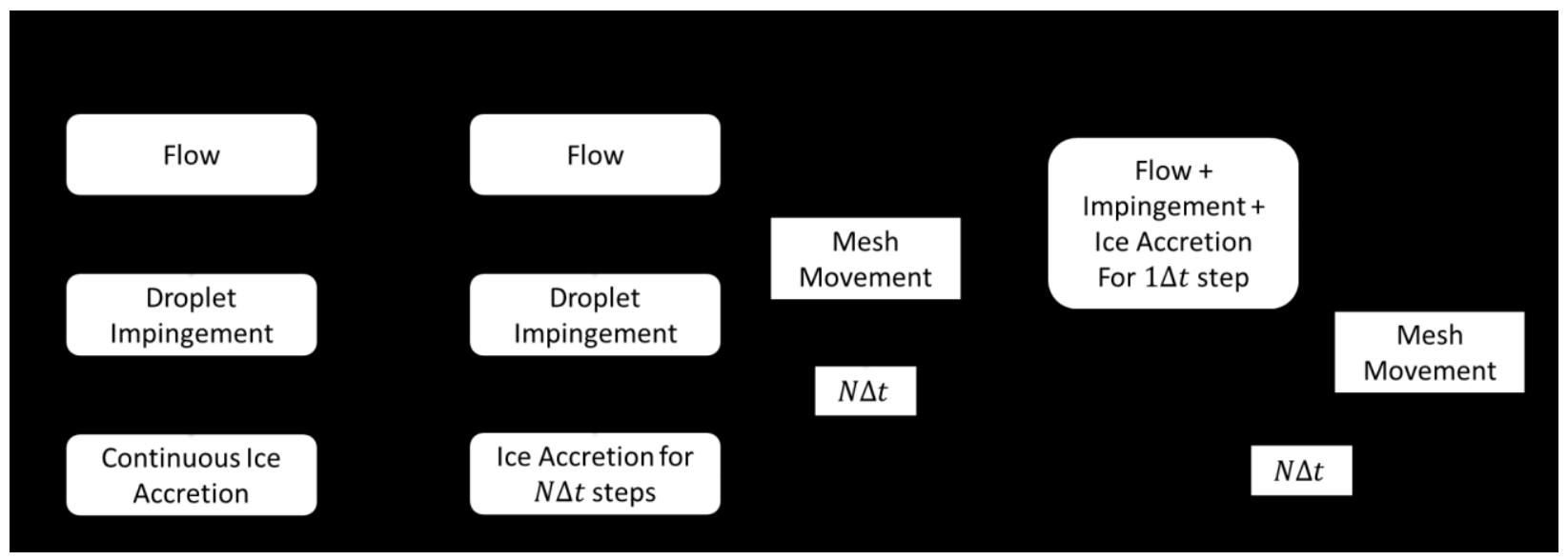

Fig. 2 One-shot, multi-shot and unsteady ice accretion configuration of FENSAP-ICE. 

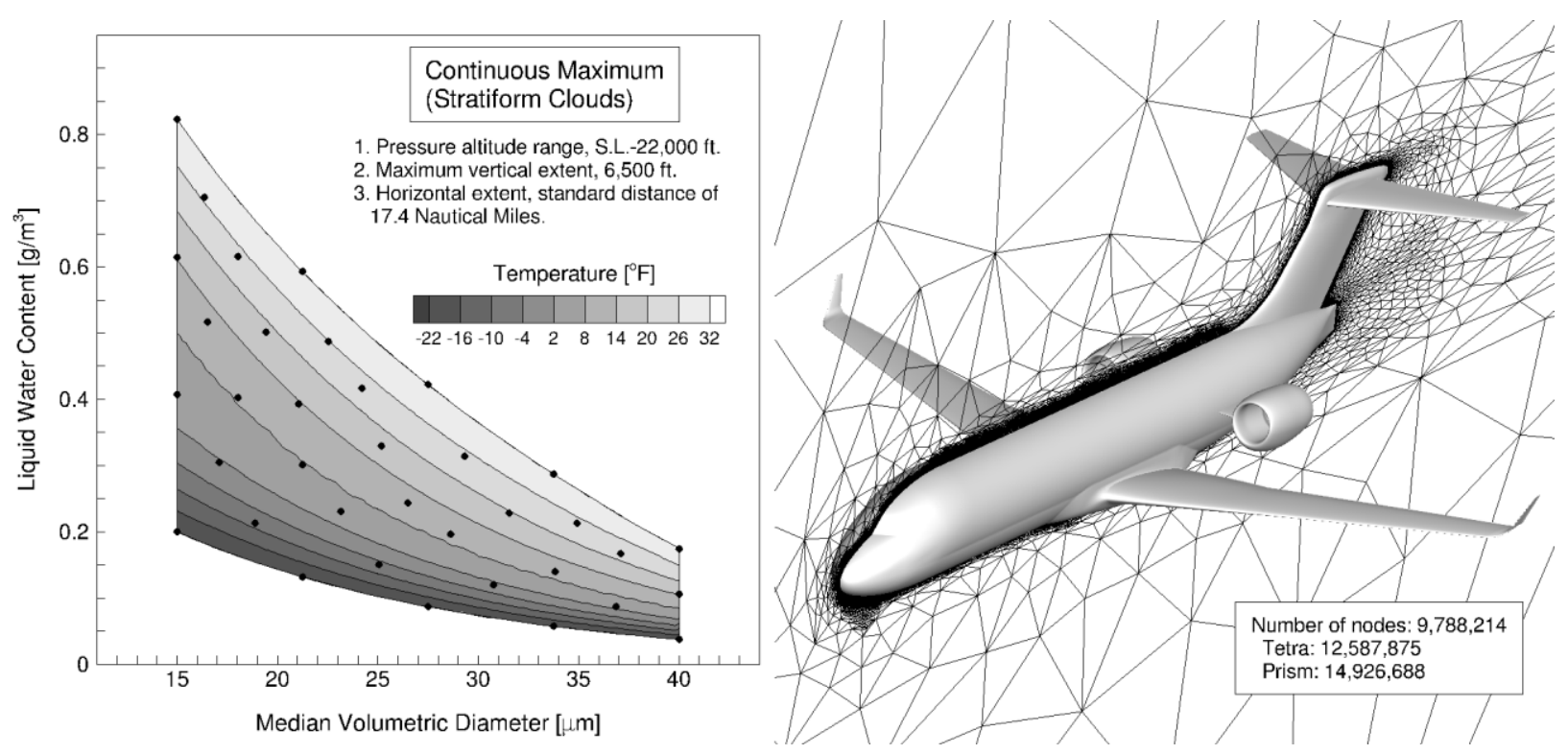

Fig. 3 Continuous maximum icing envelope, with initial sampling (left); geometry and mesh of the RJ (right).

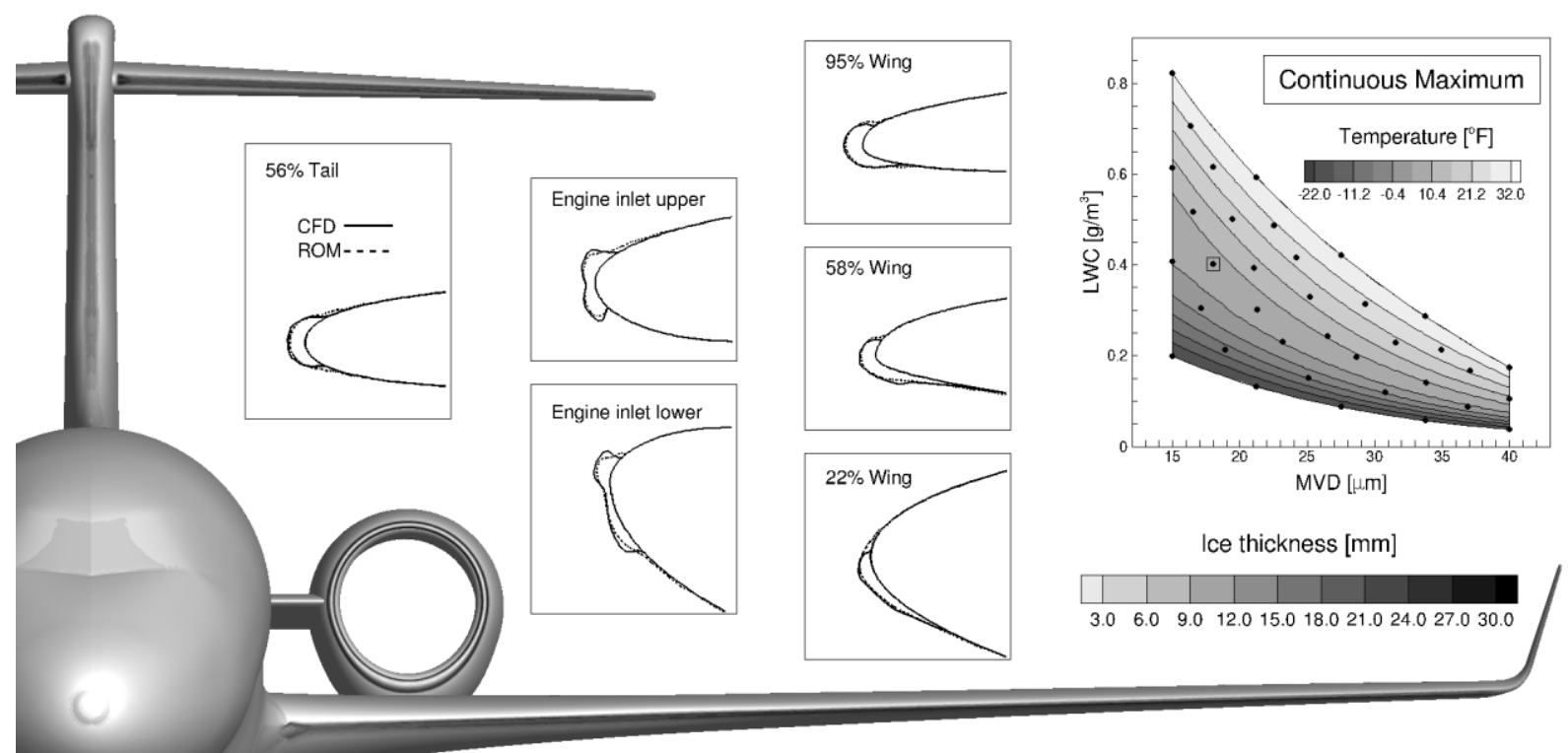




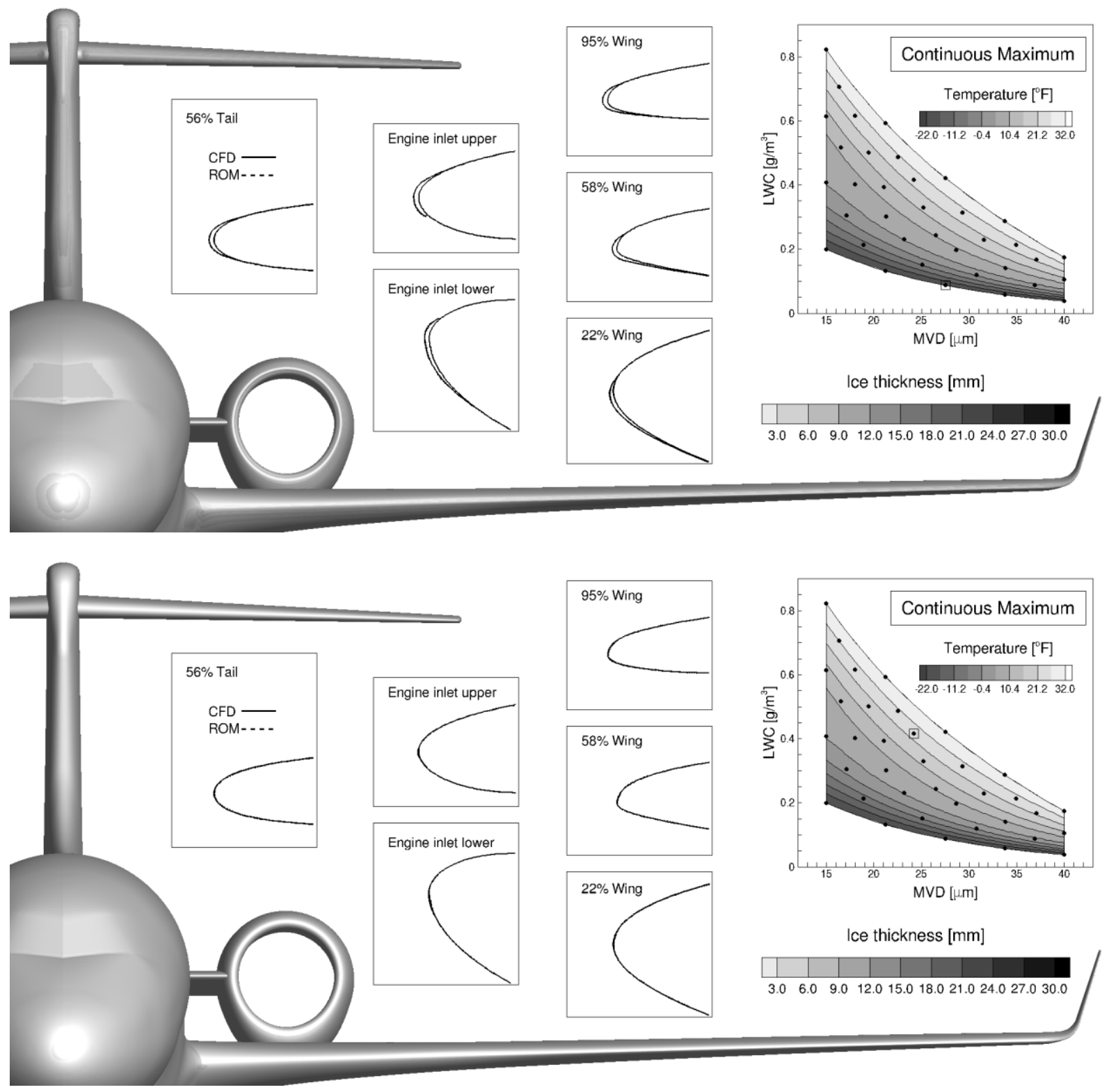

Fig. 4 Contours of ice thickness, glaze ice (top), rime ice (middle) and trace ice (bottom). 

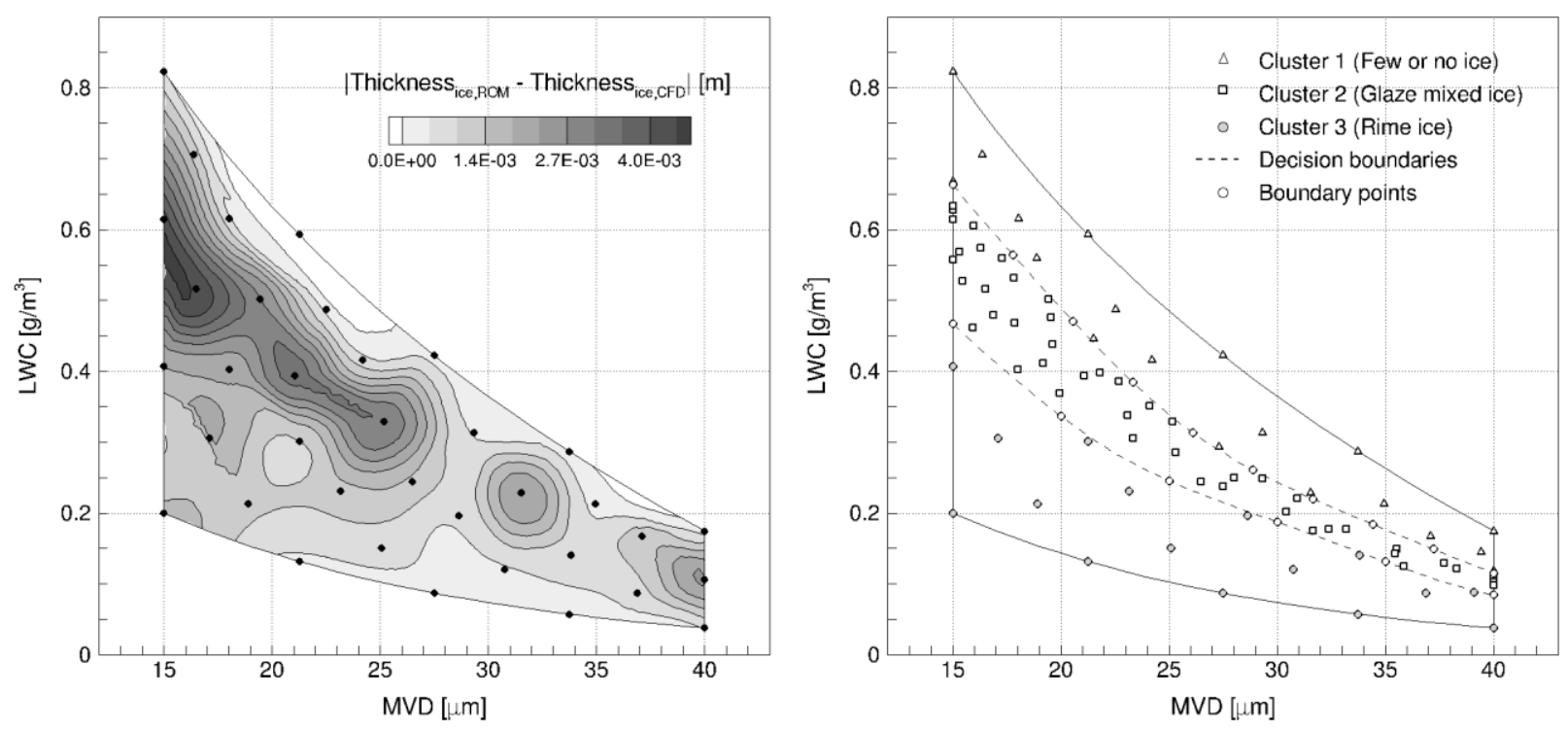

Fig. 5 Global ROM LOOCV errors for the initial sampling (left); snapshots and clustering after 6 iterations (right).
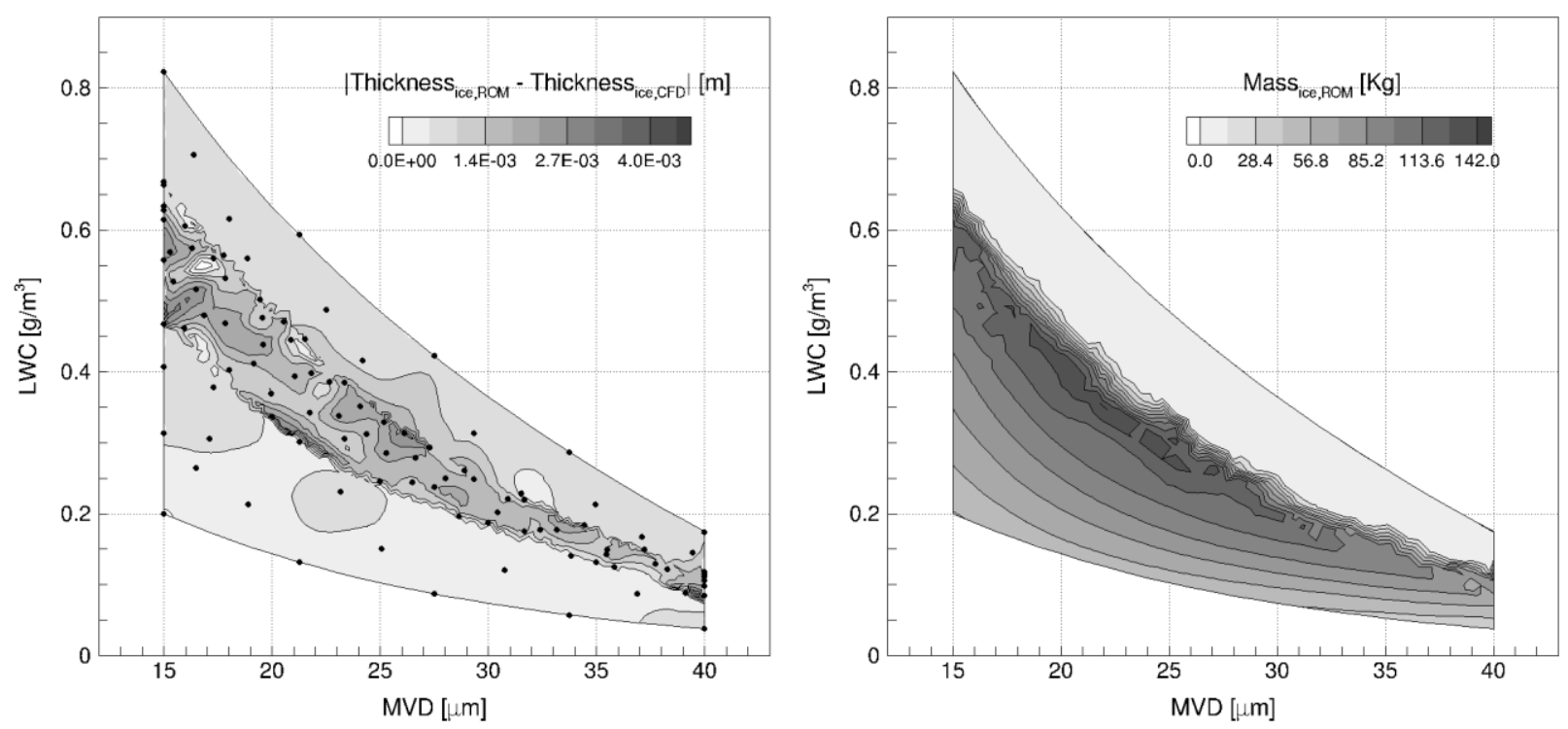

Fig. 6 Local ROM LOOCV errors for the last sampling iteration (left); mass of ice contours obtained from 1,000 ROM solutions (right). 


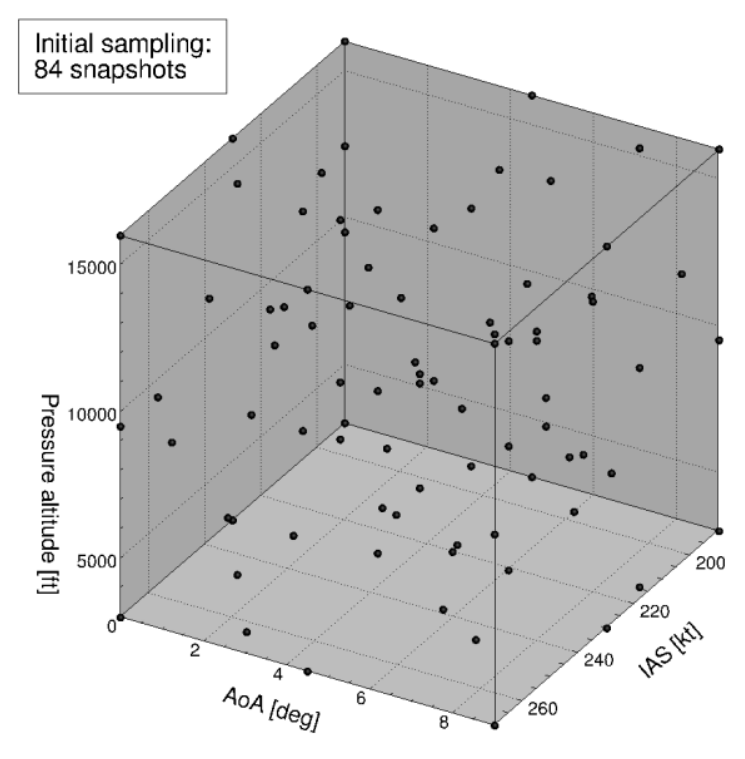

Fig. 7 Initial sampling of 84 snapshots.
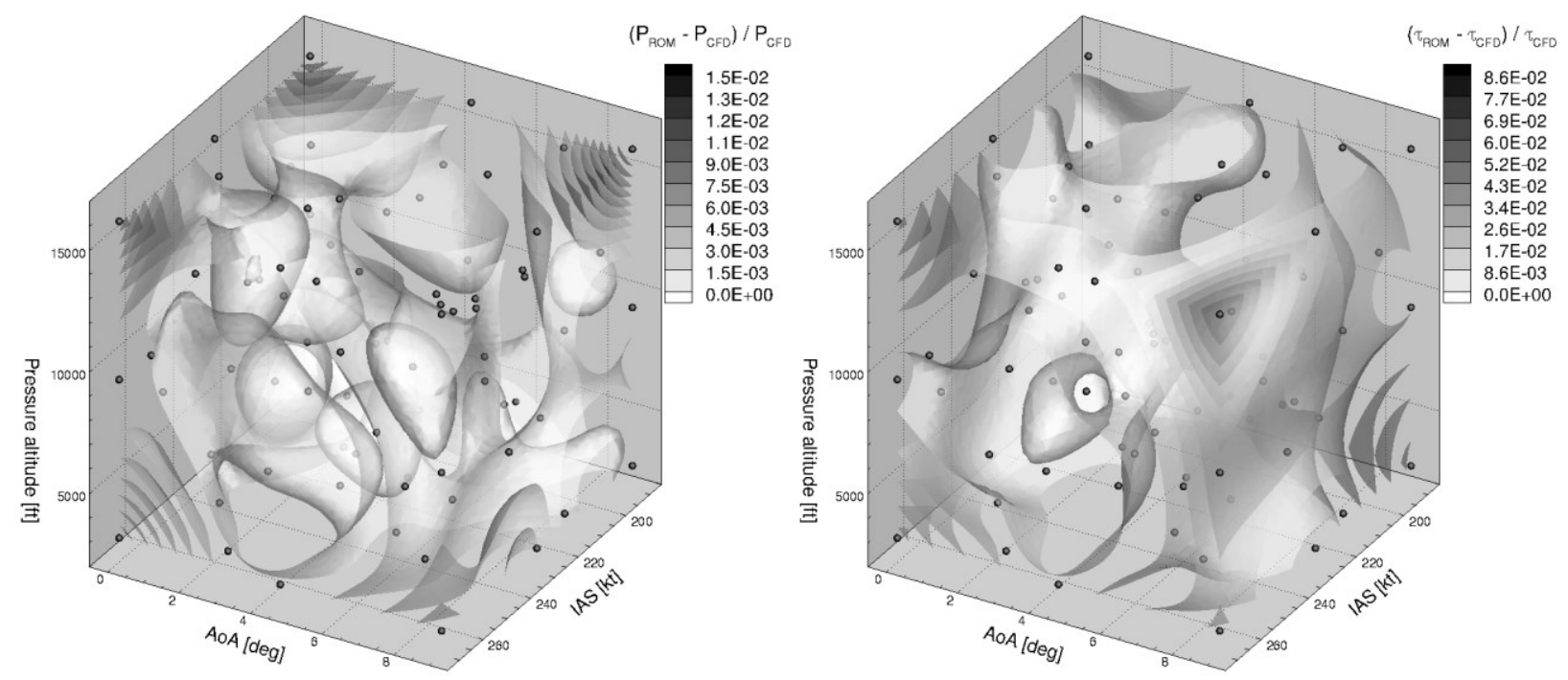

Fig. 8 LOOCV error of the initial sampling: pressure (left) and shear stress (right) over iced RJ. 

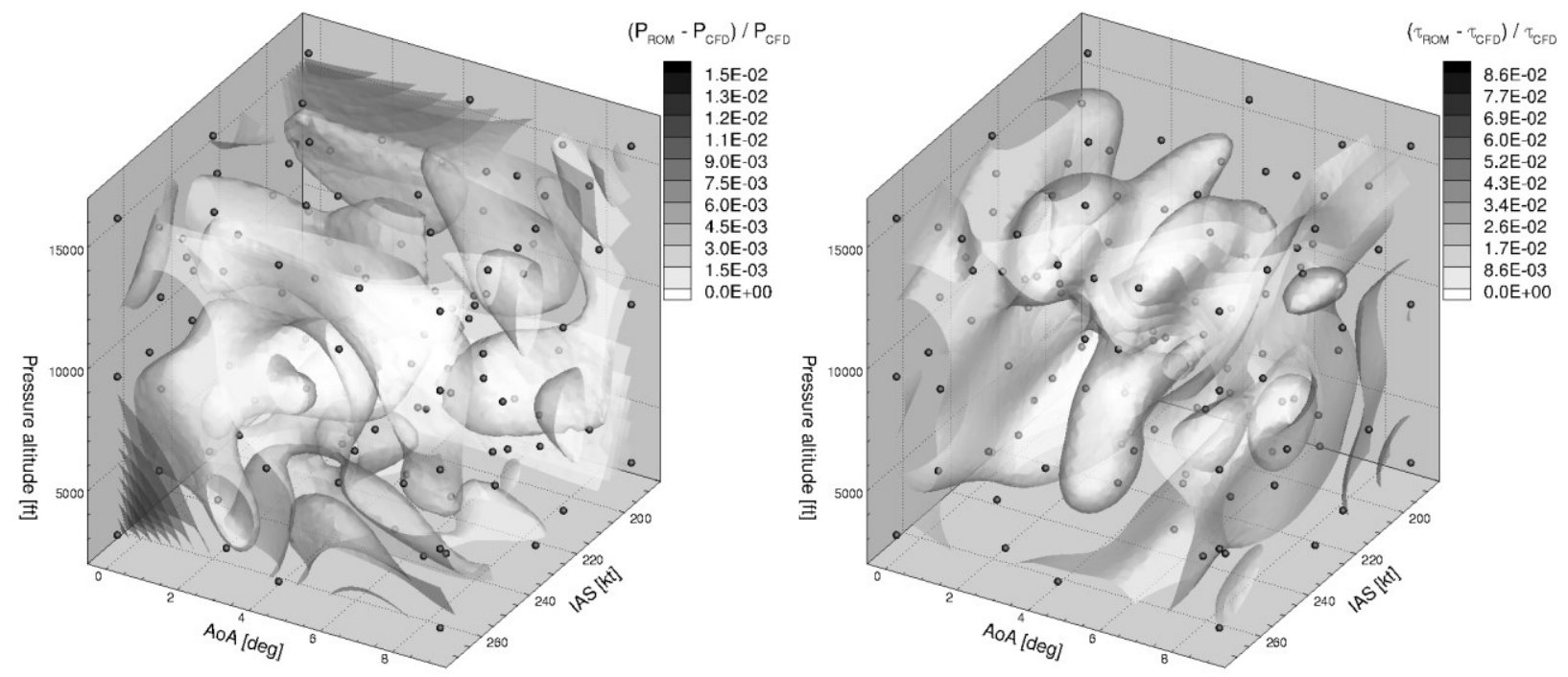

Fig. 9 LOOCV error of the final sampling, pressure (left) and shear stress (right) over iced RJ.
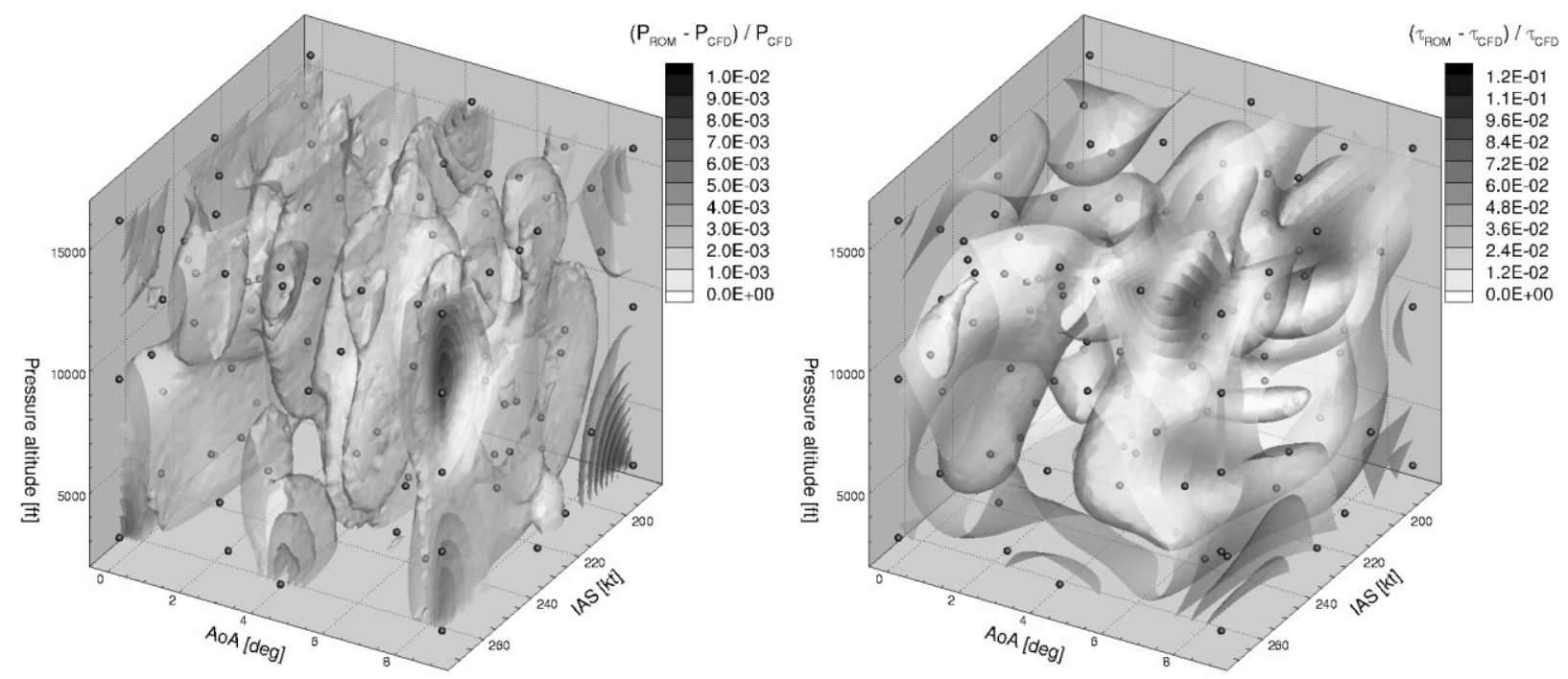

Fig. 10 LOOCV error of the final sampling, pressure (left) and shear stress (right) of clean RJ.
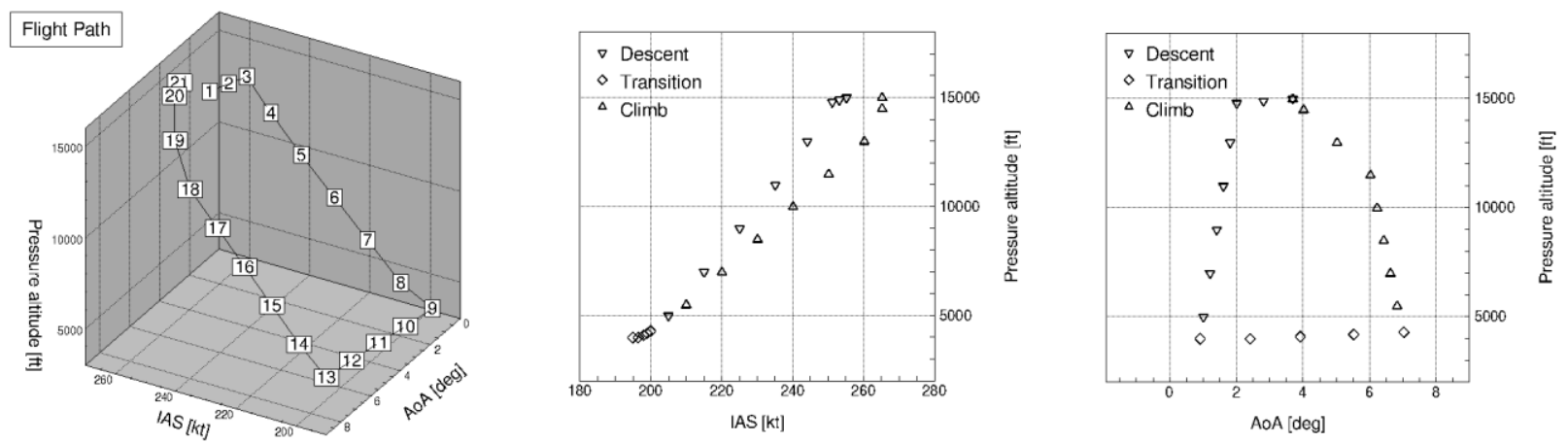
Fig. 11 Flight path simulating an aborted descent.
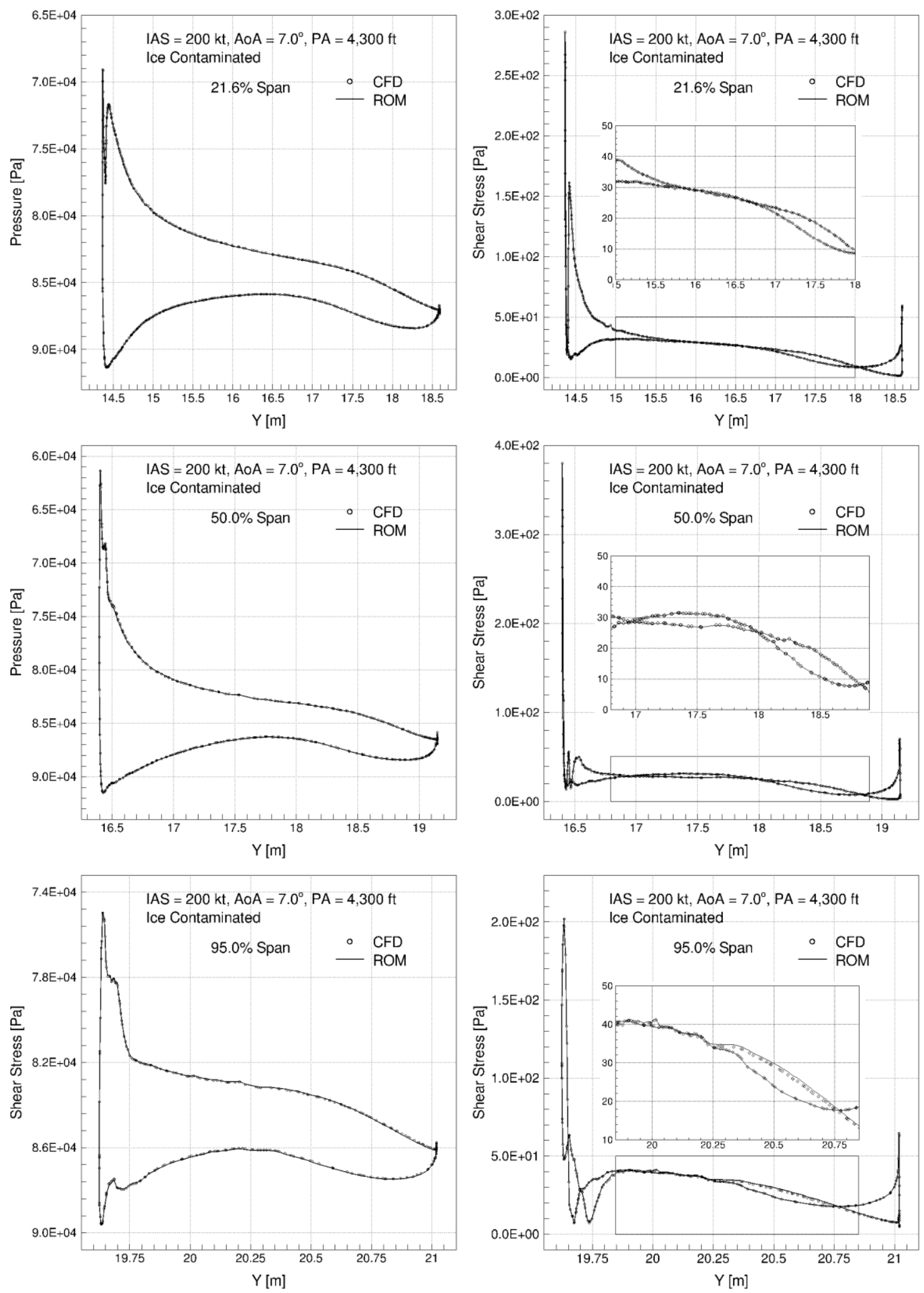

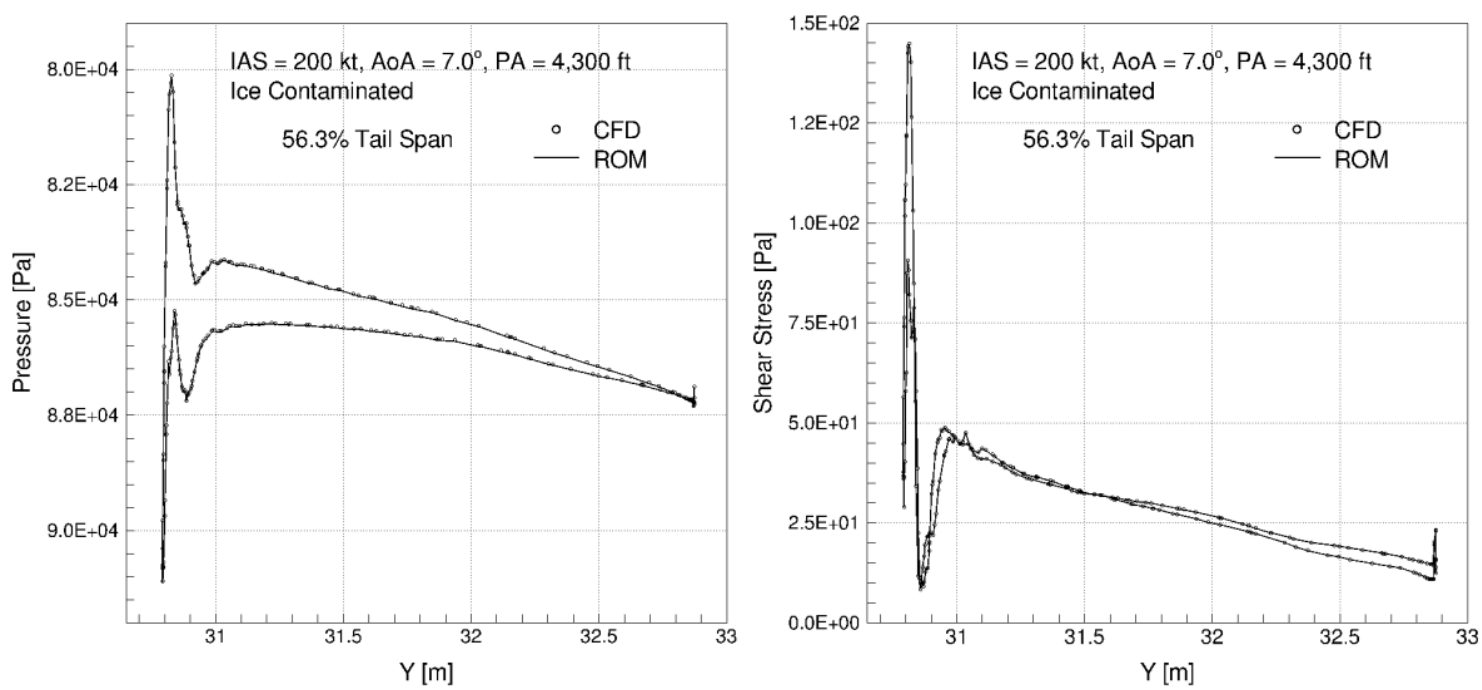

Fig. 12 ROM vs. CFD comparison of pressure coefficient and shear stress, over iced geometry, target 13.
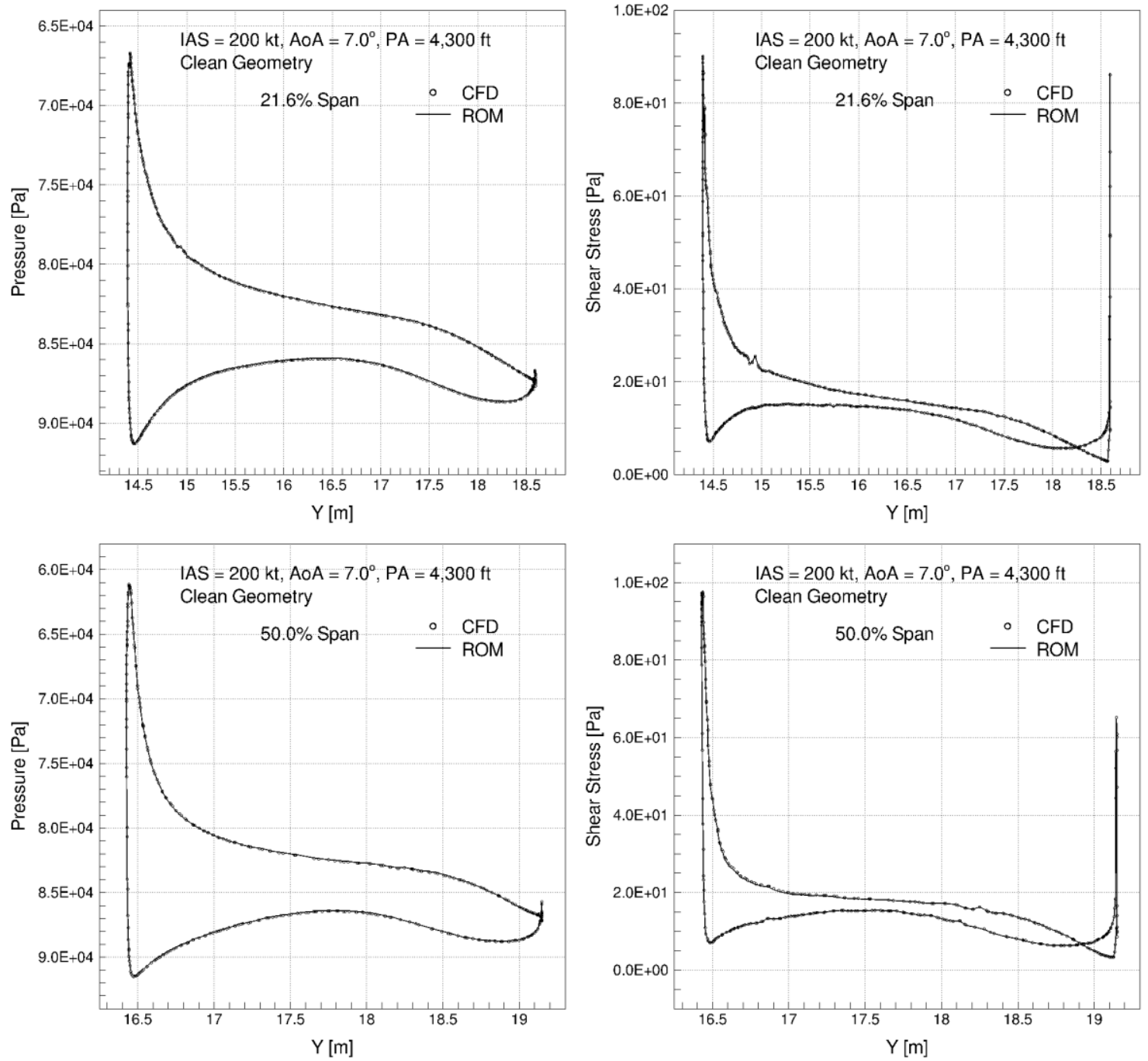

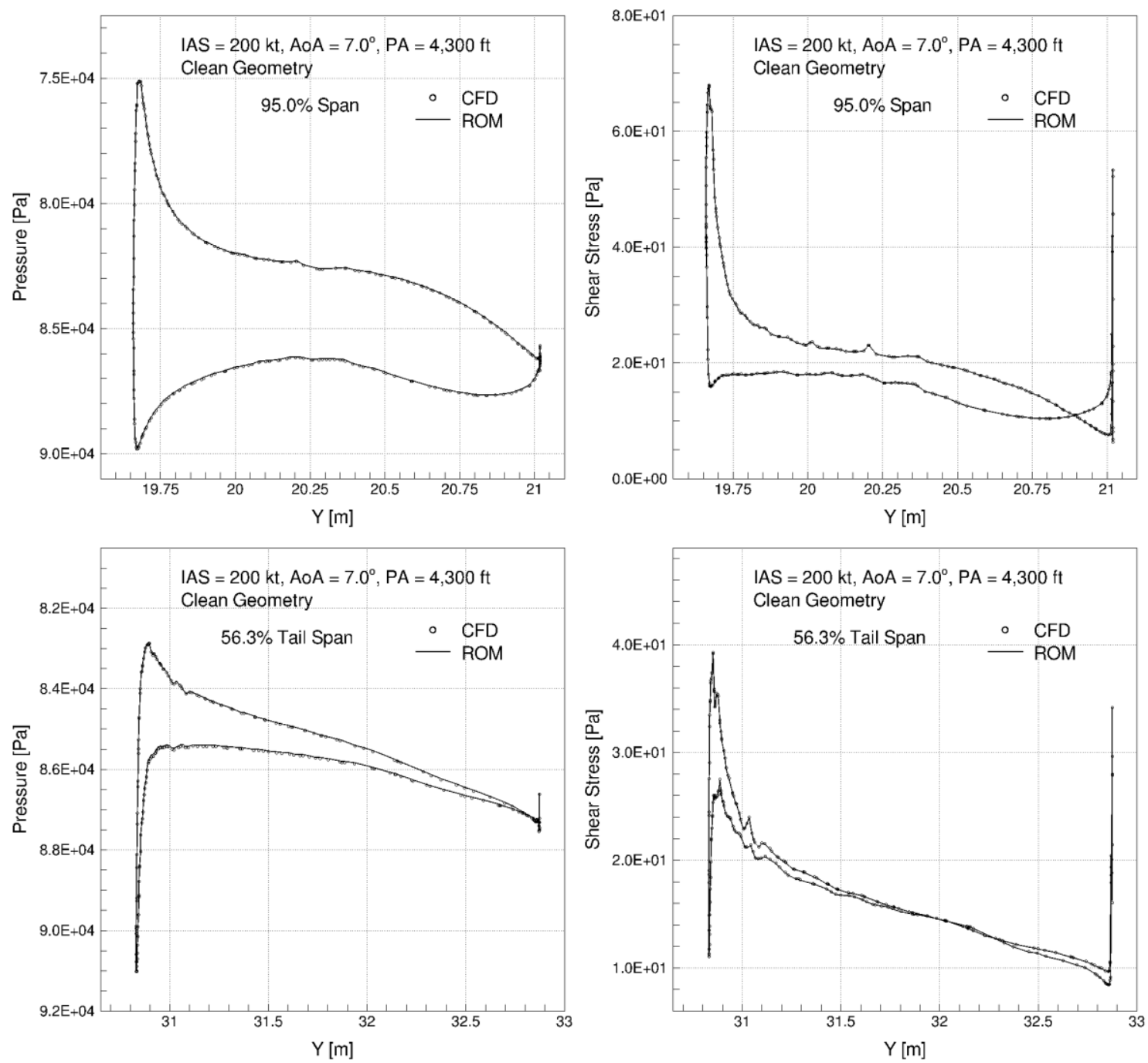

Fig. 13 ROM vs. CFD comparison of pressure coefficient and shear stress, over clean geometry, target 13.
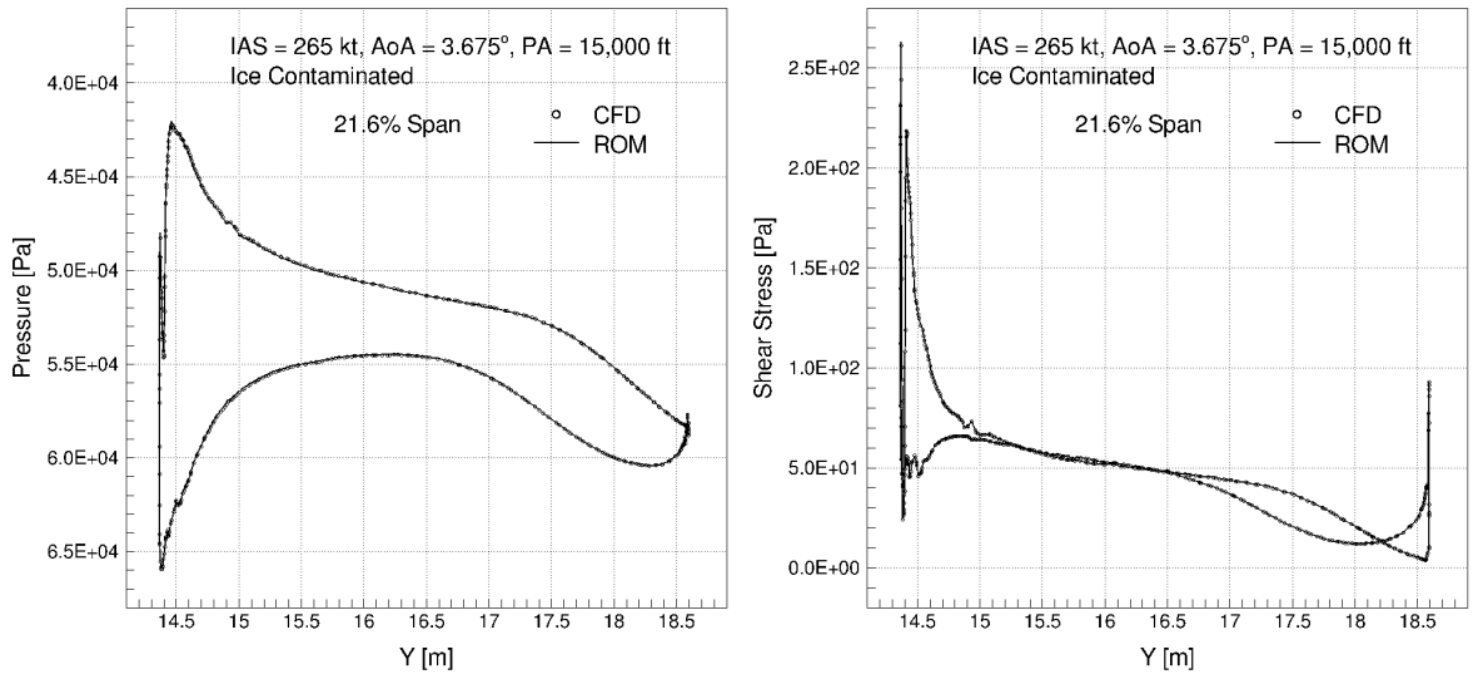

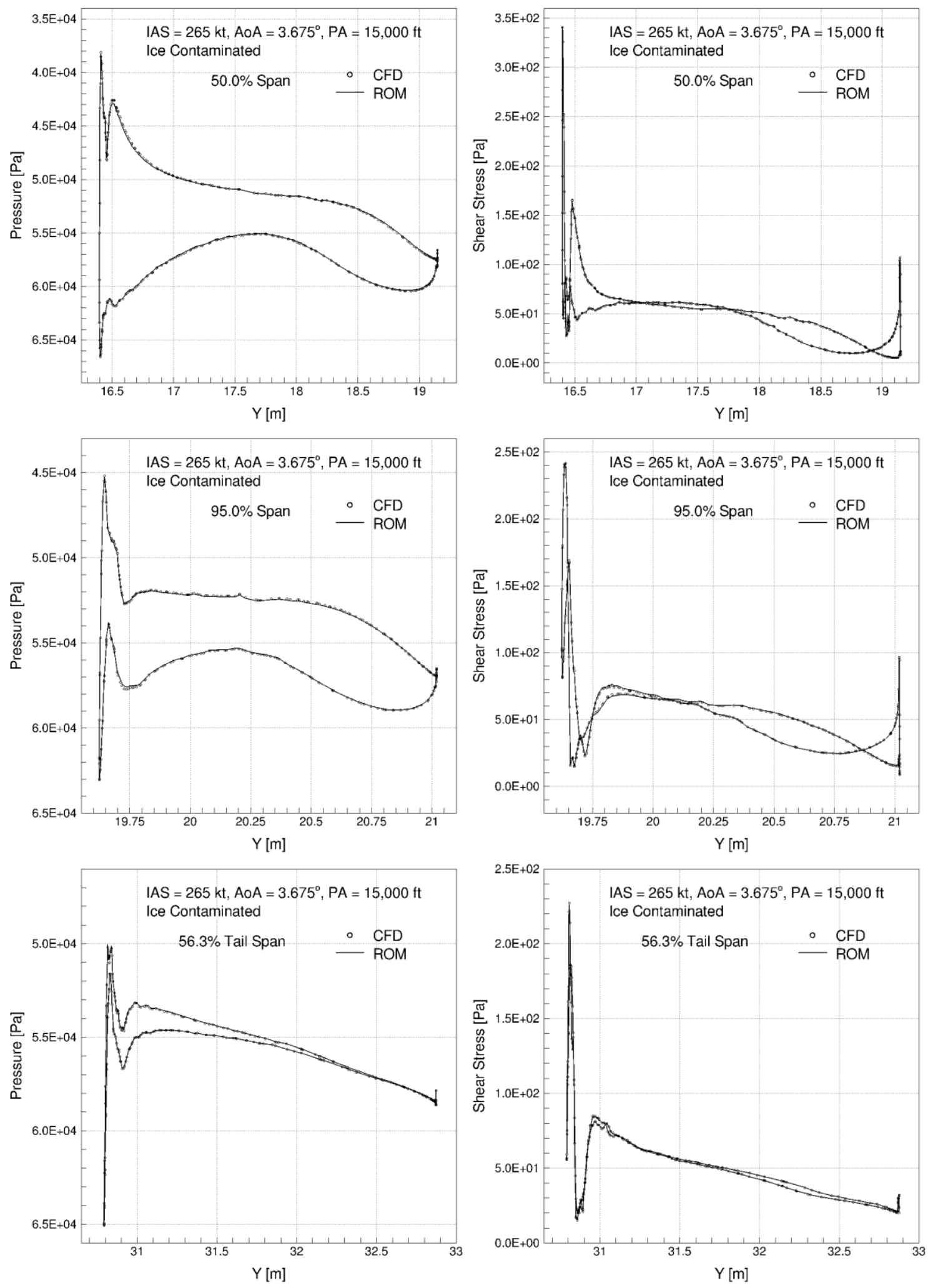

Fig. 14 ROM vs. CFD comparison of pressure coefficient and shear stress, over iced geometry, target 21. 

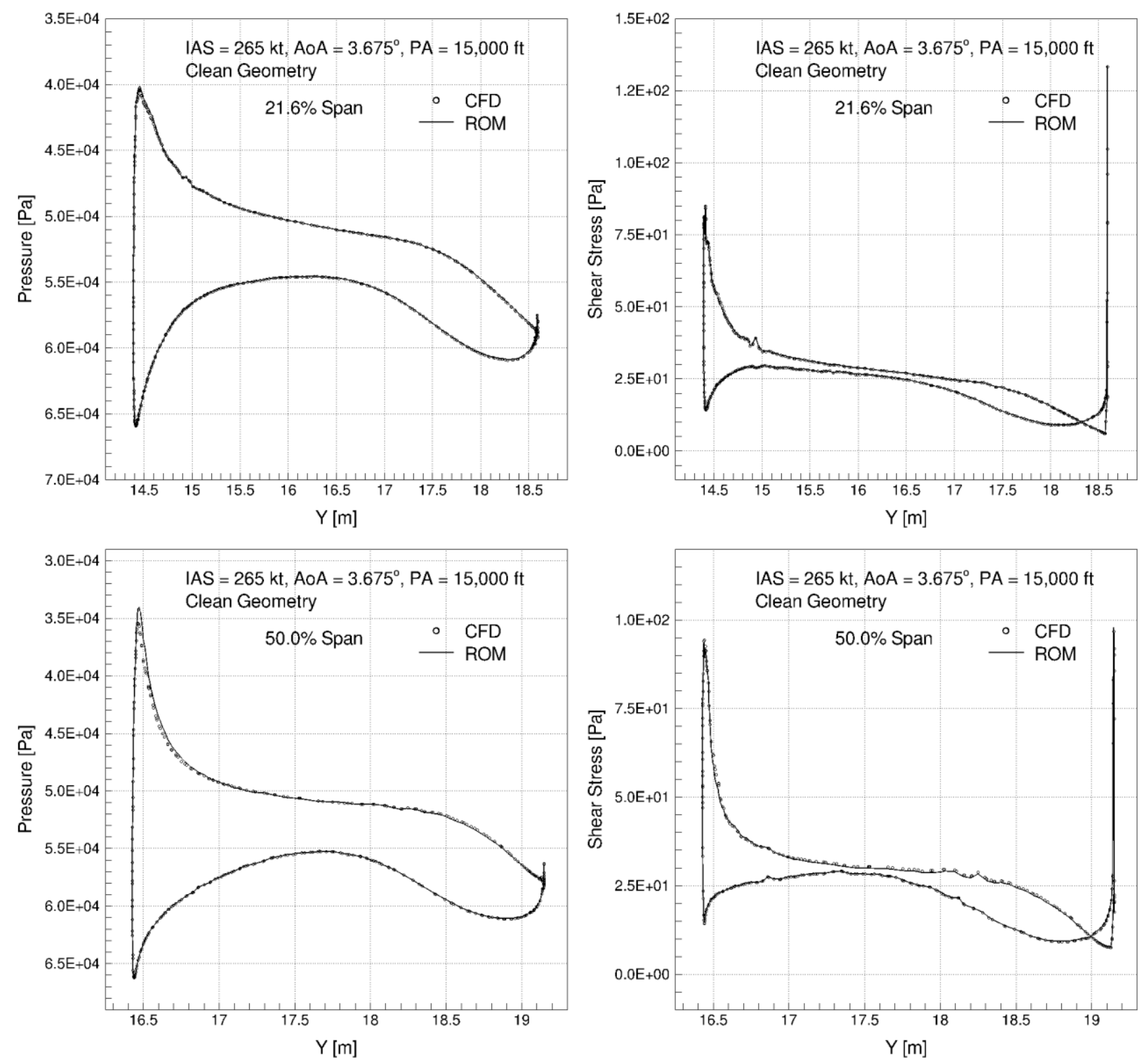

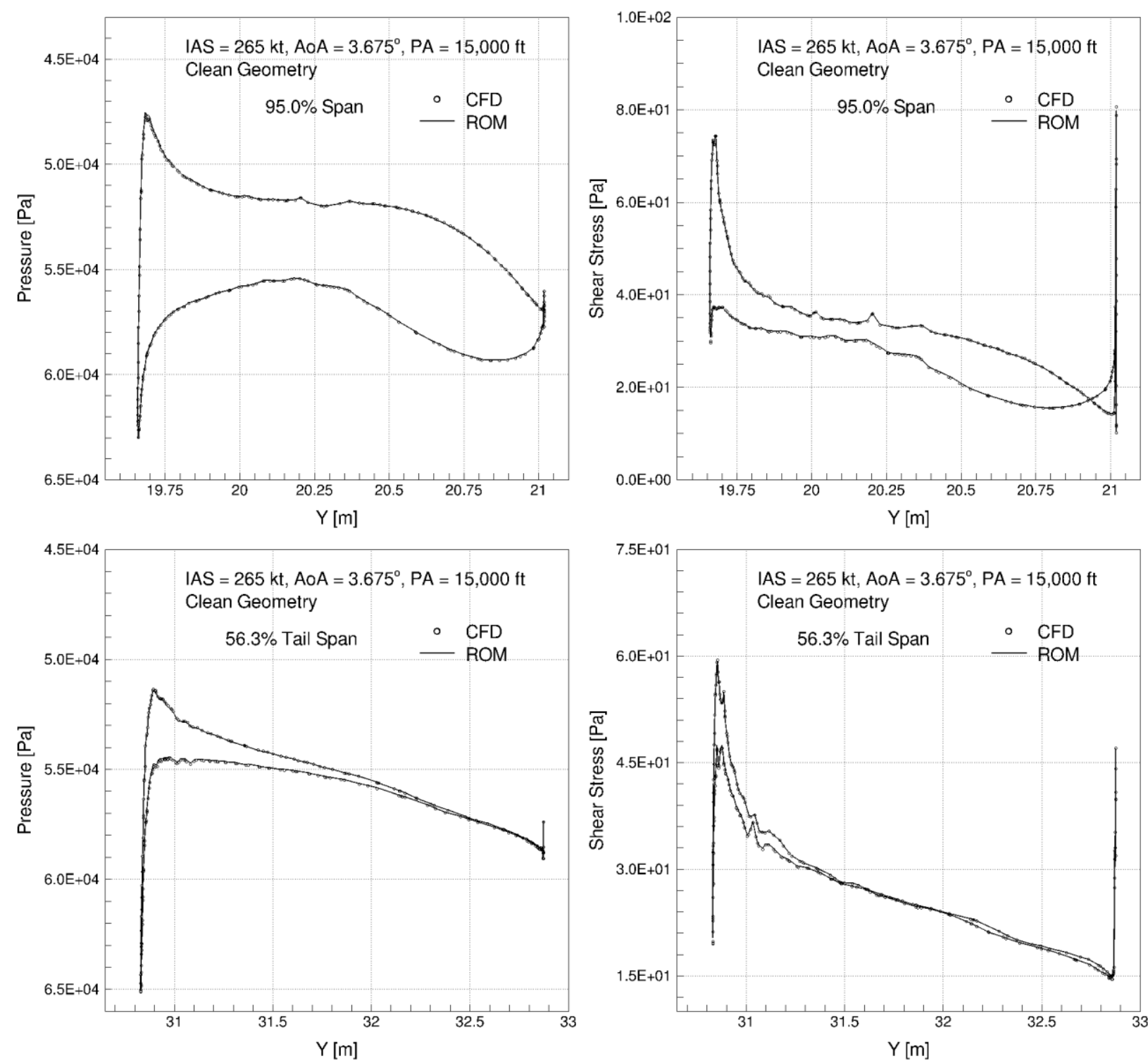

Fig. 15 ROM vs. CFD comparison of pressure coefficient and shear stress, over clean geometry, target 21.
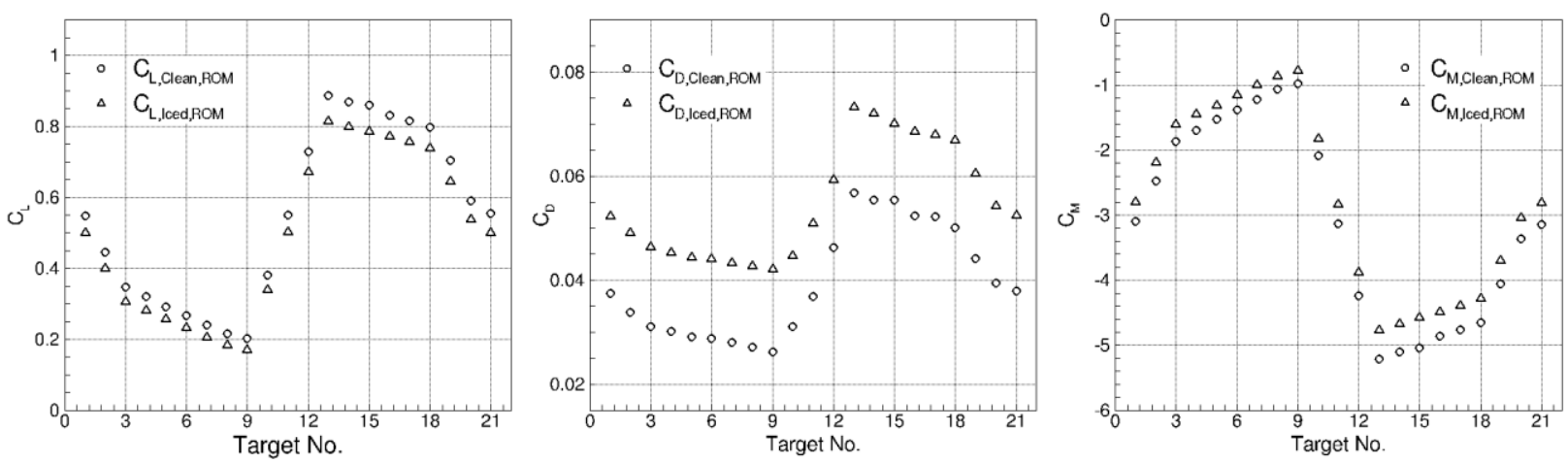

Fig. 16 Aerodynamic degradations in $C_{L}, C_{D}$ and $C_{M}$. 


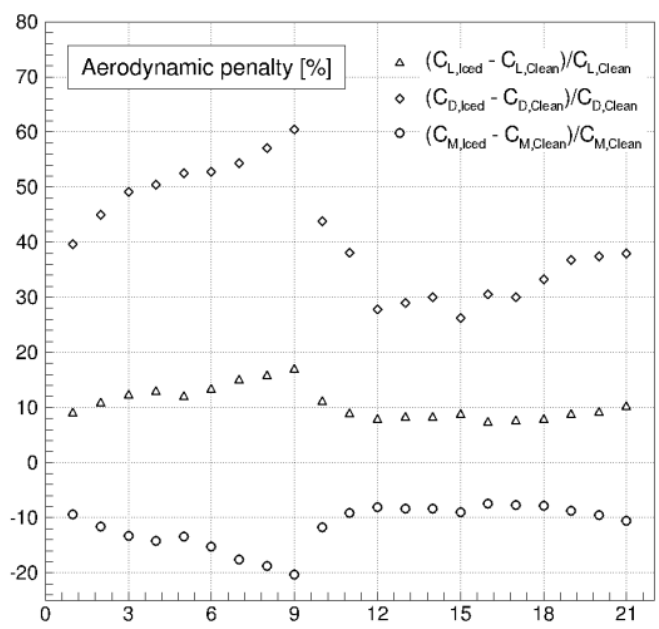

Fig. 17 Aerodynamic penalty for ice contaminated airplane. 